\title{
Regulation of sonic hedgehog-GL/1 downstream target genes PTCH1, Cyclin D2, Plakoglobin, PAX6 and NKX2.2 and their epigenetic status in medulloblastoma and astrocytoma
}

Mehdi H Shahi ${ }^{1,2,3}$, Mohammad Afzal ${ }^{2}$, Subrata Sinha ${ }^{3}$, Charles G Eberhart ${ }^{4}$, Juan A Rey ${ }^{5}$, Xing Fan ${ }^{6}$, Javier S Castresana ${ }^{1 *}$

\begin{abstract}
Background: The Sonic hedgehog (Shh) signaling pathway is critical for cell growth and differentiation. Impairment of this pathway can result in both birth defects and cancer. Despite its importance in cancer development, the Shh pathway has not been thoroughly investigated in tumorigenesis of brain tumors. In this study, we sought to understand the regulatory roles of GLII, the immediate downstream activator of the Shh signaling pathway on its downstream target genes PTCH1, Cyclin D2, Plakoglobin, NKX2.2 and PAX6 in medulloblastoma and astrocytic tumors.
\end{abstract}

Methods: We silenced GLI1 expression in medulloblastoma and astrocytic cell lines by transfection of siRNA against GLI1. Subsequently, we performed RT-PCR and quantitative real time RT-PCR (qRT-PCR) to assay the expression of downstream target genes PTCH1, Cyclin D2, Plakoglobin, NKX2.2 and PAX6. We also attempted to correlate the pattern of expression of GLI1 and its regulated genes in 14 cell lines and 41 primary medulloblastoma and astrocytoma tumor samples. We also assessed the methylation status of the Cyclin D2 and PTCH1 promoters in these 14 cell lines and 58 primary tumor samples.

Results: Silencing expression of GL/1 resulted up-regulation of all target genes in the medulloblastoma cell line, while only PTCH1 was up-regulated in astrocytoma. We also observed methylation of the cyclin D2 promoter in a significant number of astrocytoma cell lines (63\%) and primary astrocytoma tumor samples (32\%), but not at all in any medulloblastoma samples. PTCH1 promoter methylation was less frequently observed than Cyclin D2 promoter methylation in astrocytomas, and not at all in medulloblastomas.

Conclusions: Our results demonstrate different regulatory mechanisms of Shh-GL/1 signaling. These differences vary according to the downstream target gene affected, the origin of the tissue, as well as epigenetic regulation of some of these genes.

\section{Background}

The Sonic hedgehog (Shh) signaling pathway is crucial for embryonic development and is involved in the fate of many tissues during organogenesis, including the central nervous system [1-4]. Additionally, the Shh signaling pathway has been implicated in stem cell renewal [5] as

\footnotetext{
* Correspondence: jscastresana@unav.es

'Brain Tumor Biology Unit-CIFA, University of Navarra School of Sciences, Pamplona, Spain

Full list of author information is available at the end of the article
}

well as in the development of tumors such as medulloblastoma $[1,6]$, prostate cancer $[2,7,8]$ colorectal carcinoma [9], and glioma [10].

This pathway is initiated by ligation of the Shh protein with its receptor PTCH1 on a target cell. Its binding relieves the inhibition of Smoothened (SMO) by PTCH1. The active $S M O$ enters the cytoplasm and activates GLI1. GLI1 is then phosphorylated by the fused serine/ threonine kinase [11] and Costal-2, a kinase-like cytoplasmic protein (Cos2) [12], and finally enters the 
nucleus where it acts as a transcriptional regulator on the promoter regions of different target genes. Downstream target genes of GLI1 are PTCH1, Wnt, as well as other genes such as Cyclin D2 and Plakoglobin. These genes have consensus sequences for GLI1 binding in their 5 'upstream promoter region. Reports have shown that Cyclin D2 is up-regulated while Plakoglobin is down-regulated by GLI1 in epithelial transformed cell lines [13].

Direct regulation of $P A X 6$ and NKX2.2 by GLI1 has not yet been reported. However, Shh signaling regulates expression of these genes during the early embryonic stage of neuronal development. PAX6 is down-regulated and NKX2.2 is up-regulated by Shh in a dose dependent manner [14]. PAX6 also inhibits glioma invasion and acts as a tumor suppressor gene $[15,16]$. NKX2.2 is expressed in low-grade gliomas but not in high-grade gliomas [17]. However, direct regulation of these genes by GLI1 has not been studied in major brain tumors such as medulloblastomas and astrocytomas.

Reports have shown that medulloblastomas arise from granule cell progenitors $(\mathrm{GCP}) \backslash[18,19]$ by two postulated mechanisms: either excessive signaling stimulating GCP proliferation, or absence of appropriate signals for GCPs to stop dividing [20]. The role of Shh signaling pathway in medulloblastoma tumor development had its origins in the Gorlin syndrome, also known as the basal cell carcinoma syndrome, an autosomal dominant disease with an incidence of about 1 in 50,000 live births. Gorlin syndrome is caused by PTCH1 mutations in about $85 \%$ of cases. At least $25 \%$ of medulloblastoma sporadic tumors show PTCH1 mutations [21]. The major focus of medulloblastoma tumor research is now based upon GCPs as a source of medulloblastoma, although certain populations of neural stem cells (NSCs) are gaining importance [22,23]. The role of Shh signaling is less well studied in astrocytomas. Additionally, the involvement of GLI1 downstream target genes such as PTCH1, Cyclin D2, Plakoglobin, NKX2.2 and PAX6 have not been studied in either tumor.

In our study, we have silenced expression of GLI1 using a small interfering RNA (siRNA), followed by the determination of gene expression patterns of PTCH1, Cyclin D2, Plakoglobin, NKX2.2 and PAX6 in 14 cell lines and 41 primary medulloblastoma and astrocytoma tumor samples.

Our observations on the expression of GLI1, Cyclin D2, and PTCH1 in astrocytoma cell lines as well as tumor samples revealed a significant proportion of samples showing low or null levels of Cyclin D2 and PTCH1, even in the presence of high GLI1 expression. However, high levels of GLI1 correlated with high levels of Cyclin D2 and PTCH1 in medulloblastoma cell lines and tumor samples.
We also explored the possibility of epigenetic regulation of Cyclin D2 and PTCH1 in astrocytic cell lines and samples. We used demethylating agents including 5-Aza-2'-deoxycytidine (5-Aza-2'-dC) and the histone deacetylase (HDAC) inhibitor Trichostatin A, to assess reversal of expression of Cyclin D2 in astrocytic cell lines wherein the gene is not naturally expressed. To further our understanding of epigenetic regulation, we also monitored the methylation status of the Cyclin D2 and PTCH1 promoters in 14 cell lines and 58 tumor samples derived from medulloblastomas and astrocytomas. We performed melting curve analysis-methylation assays (MCA-Meth) and melting curve analysis-methylated specific PCR (MCA-MSP) to assess methylation at these genetic loci [24].

Thus, our objectives were two-fold: first, to determine whether GLI1 up-regulates any of its downstream effectors; and second, to study potential epigenetic regulation of PTCH1 and Cyclin D2.

\section{Methods \\ Cell lines}

For this study, we chose 6 medulloblastoma cell lines (TE671, PFSK-1, Daoy, TE671c2, D283Med and SK-PNDW) and 8 high-grade astrocytoma cell lines (U87MG, A172, LN405, SW1783, T98G, SW1088, CCF-STTG1, and GOS-3). The cell lines PFSK-1, Daoy, D238, SK-PN-DW, CCF-STTG1, SW1088 and SW1783 were purchased from the American Type Culture Collection (Manassas, VA, USA). A172, T98G and U87MG were purchased from the European Collection of Cell Culture (Salisbury, Wiltshire, UK). TE671, TE671c2, LN405 and GOS-3 were obtained from the Deutsche Sammlung von Mikroorganismen und Zellkulturen (Braunschweig, Germany). The cell lines were cultured in RPMI L-Glutamax medium (GIBCO-BRL, Gaithersburg, MD, USA), supplemented with $10 \%$ fetal bovine serum (FBS), $1 \%$ penicillin/streptomycin, $0.1 \%$ amphotericin $\mathrm{B}$, and for medulloblastoma cell lines, $10 \%$ non-essential amino acids (NEAs). Cells lines were maintained at $37^{\circ} \mathrm{C}$ in the presence of $5 \% \mathrm{CO}_{2}$. On attaining $80 \%$ confluence, the cells were split using trypsin/EDTA $(1 \times)$ and plated in new sterile flasks.

\section{Primary tumor samples}

We used 14 primary medulloblastomas (Tables 1 and 2) and 44 primary astrocytomas (Tables 3 and 4). The use of medulloblastoma samples for research purposes was approved by Johns Hopkins Medical Institute (JHMI), USA Institutional Review Board under protocol \#99-1229-05. Similarly, the use of astrocytoma samples was approved by the Ethical Committee of the University of Navarra Medical School, Pamplona, Spain under the protocol \#38/2002, February and 04/2/2008. 
Table 1 Promoter methylation and expression correlation of Cyclin D2 and PTCH1 gene in medulloblastoma cell lines

\begin{tabular}{|c|c|c|c|c|c|c|c|}
\hline $\begin{array}{l}\text { Cell } \\
\text { lines }\end{array}$ & $\begin{array}{l}\text { Cyclin D2 } \\
\text { expression }\end{array}$ & $\begin{array}{l}\text { Cyclin D2 } \\
\text { promoter } \\
\text { hypermethylation } \\
\text { by MCA-Meth }\end{array}$ & $\begin{array}{l}\text { Cyclin D2 } \\
\text { Hypermethylation } \\
\text { by MSP }\end{array}$ & $\begin{array}{l}\text { Cyclin D2 } \\
\text { Hypermethylation } \\
\text { by both methods }\end{array}$ & $\begin{array}{l}\text { No Hyper } \\
\text { Methylation in } \\
\text { Cyclin D2 } \\
\text { Promoter }\end{array}$ & $\begin{array}{l}\text { PTCH1 Expression } \\
\text { in } \\
\text { medulloblastoma } \\
\text { cell lines }\end{array}$ & $\begin{array}{l}\text { PTCH1 promoter } \\
\text { Hypermethylation } \\
\text { by MCA-MSP } \\
\text { method }\end{array}$ \\
\hline TE671 & ++ & U & $M$ & & & ++ & U \\
\hline PFSK-1 & ++ & $M$ & $M$ & $\sqrt{ }$ & & ++ & U \\
\hline Daoy & ++ & U & $\mathrm{U}+\mathrm{M}$ & & & ++ & U \\
\hline TE671c2 & ++ & U & $\mathrm{U}+\mathrm{M}$ & & & + & U \\
\hline D283 & ++ & U & $U+M$ & & & + & $\mathrm{U}+\mathrm{M}$ \\
\hline $\begin{array}{l}\text { SK-PN- } \\
\text { DW }\end{array}$ & + & $U+M$ & M & $\sqrt{ }$ & & + & U \\
\hline
\end{tabular}

DW

-: no expression; +: expression; ++: high expression; $\sqrt{ }$ : yes

The astrocytomas were of WHO grades I to IV. All samples were snap frozen immediately on resection and stored at $-80^{\circ} \mathrm{C}$. Genomic DNA, RNA and proteins were extracted from the frozen tissues.

\section{GLI1 siRNA transfection and knock-down}

For these experiments, we selected the medulloblastoma cell line Daoy, and the astrocytic cell line U87MG, which were grown in RPMI L-Glutamax medium (GIBCO-BRL, Gaithersburg, MD, USA), supplemented with $2 \%$ fetal bovine serum (FBS) at $37^{\circ} \mathrm{C}$ in the presence of $5 \% \mathrm{CO}_{2}$. We procured siRNA against the GLI1 gene from Stealth ${ }^{\mathrm{Tn}}$ (Invitrogen, USA) GLI1 RNAi: GCACAUACCUGCUUCGGGCAAGAUAU (GLI-HSS104170) and AUAUCUUGCCCGAAGCAGGUAGUGC (GLI-HSS104170), along with a universal negative siRNA to control for non-specific interference by the siRNA. The universal negative siRNA used was a scrambled sequence with medium GC content and does not influence expression of the target gene. The GLI1 siRNA and the scrambled siRNA were delivered to the Daoy and U87MG cell lines (100 nM/well), using Lipofectamine $^{\mathrm{Ta}} 2000$ as the transfection reagent and

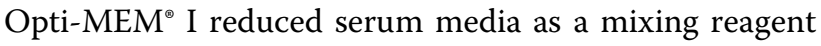
solution for the siRNA and LipofectamineTM 2000. We used BLOCK-iT ${ }^{\mathrm{Ti}}$ Fluorescent Oligo tagged with fluorescein to assess and optimize cationic lipid-mediated delivery of siRNA into the Daoy and U87MG cell lines. Following efficient transfection, we extracted RNA from cells transfected with GLI1 siRNA, scrambled siRNA, as well as untransfected cells after $72 \mathrm{~h}$. Finally, we assessed efficiency of GLI1 silencing in the two cell lines. The extracted RNA was used to assess expression levels of downstream target genes of the Shh pathway such as PTCH1, Cyclin D2, Plakoglobin, PAX6 and NKX2.2.

Table 2 Promoter methylation and expression correlation of Cyclin D2 and PTCH1 gene in medulloblastoma samples

\begin{tabular}{|c|c|c|c|c|c|c|c|c|}
\hline $\begin{array}{c}\text { MB } \\
\text { samples } \\
\text { ID }\end{array}$ & $\begin{array}{c}\text { Patients' } \\
\text { Date of } \\
\text { Birth (D/M/ } \\
\text { Y) }\end{array}$ & Sex & $\begin{array}{l}\text { Expression of } \\
\text { Cyclin D2 in } \\
\text { primary tumor } \\
\text { samples }\end{array}$ & $\begin{array}{l}\text { Promoter } \\
\text { methylation by } \\
\text { MCA-Meth in } \\
\text { Cyclin D2 }\end{array}$ & $\begin{array}{c}\text { Promoter } \\
\text { methylation } \\
\text { by MSP in } \\
\text { Cyclin D2 }\end{array}$ & $\begin{array}{l}\text { No Promoter } \\
\text { hypermethylation } \\
\text { in Cyclin D2 }\end{array}$ & $\begin{array}{c}\text { Expression of } \\
\text { PTCH1 in } \\
\text { primary tumor } \\
\text { samples }\end{array}$ & $\begin{array}{c}\text { Promoter } \\
\text { hypermethylation } \\
\text { in PTCH1 by MCA- } \\
\text { Meth of PTCH1 }\end{array}$ \\
\hline p3 & $5 / 18 / 1969$ & M & ++ & U & U & $\sqrt{ }$ & - & $U+M$ \\
\hline $\mathrm{p} 4$ & $3 / 9 / 1987$ & M & - & U & $U+M$ & & + & U \\
\hline p7 & 11/27/1987 & $M$ & ++ & U & U & $\sqrt{ }$ & + & U \\
\hline $\mathrm{p} 10$ & 4/15/1971 & M & ++ & U & U & $\sqrt{ }$ & nd & U \\
\hline $\mathrm{p} 11$ & 4/30/1997 & $\mathrm{F}$ & + & U & $U+M$ & & - & $U+M$ \\
\hline $\mathrm{p} 13$ & 8/21/1995 & $\mathrm{F}$ & + & U & $U+M$ & & nd & U \\
\hline p14 & 9/9/1991 & $\mathrm{F}$ & ++ & U & U & $\sqrt{ }$ & + & U \\
\hline $\mathrm{p} 17$ & 11/30/1988 & M & ++ & U & U & $\sqrt{ }$ & + & U \\
\hline p20 & 11/22/1978 & M & ++ & U & U & $\sqrt{ }$ & + & U \\
\hline p21 & 11/15/1987 & M & ++ & U & U & $\sqrt{ }$ & + & U \\
\hline p29 & 3/9/1974 & M & ++ & U & U & $\sqrt{ }$ & nd & U \\
\hline p30 & 6/24/1991 & M & ++ & U & U & $\sqrt{ }$ & nd & nd \\
\hline $\mathrm{p} 23$ & 8/15/1984 & $\mathrm{F}$ & nd & nd & nd & nd & nd & nd \\
\hline p52 & 10/5/1991 & M & nd & nd & nd & nd & nd & nd \\
\hline
\end{tabular}


Table 3 Cyclin D2 and PTCH1 expression and promoter hypermethylation analysis in astrocytic cell lines

\begin{tabular}{|c|c|c|c|c|c|c|c|c|}
\hline $\begin{array}{l}\text { Astrocytic } \\
\text { Cell lines }\end{array}$ & $\begin{array}{l}\text { Cyclin D2 } \\
\text { expression }\end{array}$ & $\begin{array}{l}\text { Cyclin D2 } \\
\text { Expression after } \\
\text { 5'aza+TSA }\end{array}$ & $\begin{array}{l}\text { Cyclin D2 promoter } \\
\text { hypermethylation analysis } \\
\text { by MCA-MSP }\end{array}$ & $\begin{array}{l}\text { Cyclin D2 promoter } \\
\text { hypermethylation Analysis } \\
\text { by MCA-Meth }\end{array}$ & $\begin{array}{l}\text { Cyclin D2 } \\
\text { Hypermethylation by } \\
\text { both techniques }\end{array}$ & $\begin{array}{l}\text { No } \\
\text { Hypermethylation } \\
\text { in Cyclin D2 } \\
\text { promoter }\end{array}$ & $\begin{array}{l}\text { PTCH1 } \\
\text { expression in } \\
\text { glioma cell lines }\end{array}$ & $\begin{array}{l}\text { PTCH1 promoter } \\
\text { hypermethylation by } \\
\text { MCA-MSP }\end{array}$ \\
\hline $\bar{U} 87 M G$ & + & + & $\sqrt{ }$ & $\sqrt{ }$ & $\sqrt{ }$ & & $+/-$ & \\
\hline $\bar{A} 172$ & - & + & & & & $\sqrt{ }$ & - & \\
\hline LN405 & + & + & & & & $\sqrt{ }$ & + & \\
\hline SW1783 & - & + & $\sqrt{ }$ & & & & - & \\
\hline T98G & - & ++ & $\sqrt{ }$ & $\sqrt{ }$ & $\sqrt{ }$ & & ++ & \\
\hline SW1088 & + & + & & & & $\sqrt{ }$ & ++ & \\
\hline CCF-STTG-1 & - & + & $\sqrt{ }$ & & & & ++ & $\sqrt{ }$ \\
\hline GOS-3 & - & ++ & $\sqrt{ }$ & $\sqrt{ }$ & $\sqrt{ }$ & & ++ & \\
\hline
\end{tabular}


Table 4 Expression and promoter hypermethylation analysis of Cyclin D2 and PTCH1 gene in astrocytic tumor samples

\begin{tabular}{|c|c|c|c|c|c|c|c|}
\hline $\begin{array}{l}\text { Astrocytic } \\
\text { tumor samples } \\
\text { Grade and } \\
\text { Sample ID }\end{array}$ & $\begin{array}{l}\text { Expression of } \\
\text { Cyclin D2 in } \\
\text { tumor } \\
\text { samples }\end{array}$ & $\begin{array}{l}\text { Methylation } \\
\text { by MSP in } \\
\text { Cyclin D2 } \\
\text { promoter }\end{array}$ & $\begin{array}{l}\text { Methylation by } \\
\text { MCA-Meth in } \\
\text { Cyclin D2 } \\
\text { promoter }\end{array}$ & $\begin{array}{l}\text { Methylation by } \\
\text { both techniques } \\
\text { in Cyclin D2 } \\
\text { promoter }\end{array}$ & $\begin{array}{l}\text { No } \\
\text { hypermethylation } \\
\text { in Cyclin D2 } \\
\text { promoter }\end{array}$ & $\begin{array}{l}\text { Expression } \\
\text { of PTCH1 in } \\
\text { tumor } \\
\text { samples }\end{array}$ & $\begin{array}{l}\text { Methylation of } \\
\text { PTCH1 } \\
\text { promoter by } \\
\text { MCA-Meth }\end{array}$ \\
\hline$\overline{\mathrm{GBM}(3)}$ & - & $\sqrt{ }$ & $\sqrt{ }$ & $\sqrt{ }$ & & - & $\sqrt{ }$ \\
\hline Alll(4) & ++ & & & & $\sqrt{ }$ & + & \\
\hline$\overline{G B M(5)}$ & - & & & & $\sqrt{ }$ & $+/-$ & \\
\hline$\overline{\mathrm{GBM}(6)}$ & - & $\sqrt{ }$ & & & & $+/-$ & \\
\hline$\overline{\text { AllI(7) }}$ & + & & & & $\sqrt{ }$ & $+/-$ & \\
\hline GBM(8) & - & $\sqrt{ }$ & & & & ++ & \\
\hline$\overline{\mathrm{GBM}(9)}$ & + & & & & $\sqrt{ }$ & - & \\
\hline Alll(10) & - & $\sqrt{ }$ & & & & $+/-$ & \\
\hline$\overline{G B M}(11)$ & ++ & & & & $\sqrt{ }$ & $+/-$ & \\
\hline GBM(12) & + & & & & $\sqrt{ }$ & + & \\
\hline GBM(13) & - & $\sqrt{ }$ & $\sqrt{ }$ & $\sqrt{ }$ & & + & $\sqrt{ }$ \\
\hline Alll(14) & ++ & & $\sqrt{ }$ & & & - & \\
\hline GBM(15) & - & $\sqrt{ }$ & & & & $+/-$ & \\
\hline Alll(16) & ++ & $\sqrt{ }$ & & & & $+/-$ & \\
\hline GBM(17) & - & & $\sqrt{ }$ & & & ++ & \\
\hline GBM(18) & - & $\sqrt{ }$ & $\sqrt{ }$ & $\sqrt{ }$ & & + & \\
\hline Alll(19) & + & & $\sqrt{ }$ & & & + & \\
\hline All(20) & + & & $\sqrt{ }$ & & & + & \\
\hline Alll(21) & - & $\sqrt{ }$ & & & & - & $\sqrt{ }$ \\
\hline GBM(22) & - & & $\sqrt{ }$ & & & - & \\
\hline$\overline{G B M}(23)$ & - & & $\sqrt{ }$ & & & + & \\
\hline GBM(24) & - & $\sqrt{ }$ & $\sqrt{ }$ & $\sqrt{ }$ & & + & \\
\hline $\mathrm{Al}(25)$ & ND & & & & $\sqrt{ }$ & $\mathrm{ND}$ & \\
\hline GBM(26) & ND & & & & $\sqrt{ }$ & ND & \\
\hline GBM(27) & ND & & & & $\sqrt{ }$ & ND & \\
\hline GBM(28) & ND & & & & $\sqrt{ }$ & ND & \\
\hline GBM(29) & ND & & & & $\sqrt{ }$ & ND & \\
\hline GBM(30) & + & $\sqrt{ }$ & & & & + & \\
\hline GBM(31) & ND & & & & $\sqrt{ }$ & ND & \\
\hline GBM(32) & ND & & & & $\sqrt{ }$ & ND & \\
\hline$\overline{A l(34)}$ & $\mathrm{ND}$ & & & & $\sqrt{ }$ & ND & \\
\hline Alll(35) & ND & & & & $\sqrt{ }$ & ND & \\
\hline GBM(36) & ND & & & & $\sqrt{ }$ & ND & \\
\hline$\overline{\mathrm{GBM}(41)}$ & ND & & & & $\sqrt{ }$ & ND & \\
\hline GBM(43) & + & $\sqrt{ }$ & & & & - & \\
\hline $\mathrm{GBM}(44)$ & ND & & & & $\sqrt{ }$ & ND & \\
\hline GBM(45) & ND & & & & $\sqrt{ }$ & ND & \\
\hline$\overline{\mathrm{GBM}(46)}$ & ND & & & & $\sqrt{ }$ & ND & \\
\hline$\overline{G B M}(47)$ & $\mathrm{ND}$ & & & & $\sqrt{ }$ & ND & \\
\hline GBM(48) & ND & $\sqrt{ }$ & & & & ND & \\
\hline GBM(49) & ND & $\sqrt{ }$ & & & & ND & \\
\hline All(50) & ++ & & & & $\sqrt{ }$ & - & \\
\hline$\overline{G B M}(51)$ & - & $\sqrt{ }$ & & & & - & \\
\hline$\overline{G B M}(52)$ & ++ & & & & $\sqrt{ }$ & + & \\
\hline
\end{tabular}




\section{Standard RT-PCR and quantitative real time RT-PCR (qRT-} PCR)

We used the QuickPrep Total RNA extraction Kit (Amersham Biosciences, UK) to extract RNA from the two transfected cell lines, Daoy and U87MG. Normal adult brain RNA (Stratagene, Cedar Creek, TX) was used as a control for mRNA expression. A total of $1 \mu \mathrm{g}$ of RNA was converted to cDNA by the Superscript II RNase $H$ Reverse Transcriptase kit (Invitrogen, Life Technologies, Carlsbad, CA). The cDNA was amplified by standard RT-PCR using oligonucleotides published elsewhere [9]. We compared mRNA expression in GLI1 silenced cell lines with cells transfected with scrambled siRNA as well as untransfected cell lines. We confirmed GLI1 silencing by quantifying GLI1 transcript expression in the silenced samples by qRT-PCR, and compared these levels with samples transfected with scrambled siRNA and untransfected cell lines. We also determined expression levels of Cyclin D2, Plakoglobin, NKX2.2 and PAX6 by qRT-PCR in silenced, control, and untransfected cell lines. Thereafter, we assessed the expression of these genes in 14 medulloblastoma and astrocytoma cell lines as well as 41 primary tumor samples by qRTPCR. Transcript expression of every gene was normalized to GAPDH [25]. For qRT-PCR we used $\mathrm{iQ}^{\text {tu }} \mathrm{SYBR}^{\circ}$ Green Supermix (Bio-Rad, Hercules, CA) as the fluorescence dye to monitor amplification of cDNA. Each sample was run in triplicate and the means and standard deviations were determined. We also compared expression of the candidate genes in our samples with expression in normal human brain tissue. Reaction conditions for qRT-PCR were $95^{\circ} \mathrm{C}$ for $10 \mathrm{~min}$, followed by 35 cycles of $95^{\circ} \mathrm{C}$ (denaturation) for $1 \mathrm{~min}, 57.4^{\circ} \mathrm{C}$ to $62^{\circ} \mathrm{C}$ (annealing temperature, depending on the gene amplified) for $1 \mathrm{~min}$, and $72^{\circ} \mathrm{C}$ (extension) for $50 \mathrm{~s}$. Further, melting curve analysis was carried out at $72^{\circ} \mathrm{C}$ for 1 min, and $95^{\circ} \mathrm{C}$ for 10 mins.

\section{Western blotting}

Proteins were extracted from 8 astrocytoma cell lines and 12 primary astrocytic tumor samples (randomly selected) using the RIPA buffer (0.5\% sodium deoxycolate, $0.1 \%$ SDS, $1 \%$ NP40, in $1 \times$ PBS supplemented with protease inhibitor cocktail and PMSF). We were unable to extract protein from medulloblastoma samples due to shortage of tumor samples. A total of 20-30 $\mathrm{\mu g}$ of protein per sample was loaded on a gel for western blotting. The resolved proteins were transferred onto a nitrocellulose membrane (Bio-Rad, Hercules, CA, USA). The membrane was blocked with $5 \%$ non-fat milk in TBST buffer to prevent nonspecific binding. The membrane was exposed to the primary antibody: anti-GLI1 (goat polyclonal (N-19); Santa Crux, CA, USA) and antiCyclin D2 (rabbit polyclonal (H-289) Santa Cruz, CA,
USA) antibodies at 1:400 and 1:200 dilution, respectively in $5 \%$ skim milk in TBST overnight at $4^{\circ} \mathrm{C}$. The membranes were subsequently exposed to HRP-conjugated secondary antibodies (antigoat IgG and anti-rabbit IgG at a dilution of 1:5000 in TBST) and incubated for 1-2 $\mathrm{h}$ at room temperature. Positive interaction of the antibodies with the target protein was detected by enhanced chemiluminescence (ECLTM Western Blotting Analysis System, Amersham Biosciences, Piscataway, NJ, USA) and autoradiography.

\section{Epigenetic studies of Cyclin D2 and PTCH1 promoters}

Treatment of cells with 5-aza-2'-deoxycytidine and TSA were undertaken according to our previous protocol [26]. Bisulfite modification of genomic DNA extracted from the cell lines and tumor samples was performed using the CpGenome DNA modification Kit S7820 (Chemicon International).

\section{Cyclin D2 promoter methylation analysis}

We identified three putative CpG-rich promoter regions [27]. The first CpG island ranges from -1550 to -1288 upstream of the start site (262 bp), the second from -1230 to -982 (248 bp), and the third from -296 to -104 (192 bp). These three regions contain consensus binding sequences for several transcription factors including AP2, PUF, STF, PEA3, E2F and PEA3 [27]. The consensus sequence (GCTCTGCTCGCCCACCACCCAATCCTCGCCTC) for binding of GLI1 onto the Cyclin D2 promoter region is present in the third CpG island.

We analyzed the Cyclin D2 promoter by two independent methods. The first was MCA-Meth [24] (a 108 bp product was amplified from the first $\mathrm{CpG}$ region: from -1462 to -1354$)$. The second method was MSP-PCR (primer pairs for this method were taken from a previously published article [28]). Unmethylated primers amplified the region from -1616 to -1394 (first CpG -rich region) giving a product of $222 \mathrm{bp}$; methylated primers amplified the region from -1394 to -1152 (covering the first and second CpG rich regions) producing a product of $276 \mathrm{bp}$.

\section{PTCH1 promoter methylation analysis}

We analyzed the promoter region of PTCH1 from -238 to +62 bp [29], which corresponds with exon $1 \mathrm{~B}$ [30]. To assess methylation of the PTCH1 promoter, we followed the MCA-MSP method [24]. This method gives us two melting peaks which are dependent on amplification with unmethylated or methylated primers.

\section{Statistical analysis}

Statistical analyses were performed using Graphpad Prism 4 (Graphpad Software Inc., San Diego, CA). Data 
graphed with error bars represent mean and SD from experiments performed in triplicate, unless otherwise noted. Fisher's exact test was used to determine the significance of any difference.

\section{Results}

\section{Expression of GLI1 target genes after siRNA-mediated} GLI1 silencing

We transfected Daoy and U87MG cell lines with GLI1 siRNA and scrambled siRNA. We monitored the efficiency of transfection using lipofectamine through the delivery of the BLOCK-iT ${ }^{\mathrm{sm}}$ Fluorescent Oligo (Figures $1 \mathrm{~A}-\mathrm{F})$. Images were captured using a fluorescent imaging microscope and similar efficiencies of transfection were attained for both the GLII siRNA and the scrambled siRNA. To assess efficiency of silencing, expression of GLI1 was monitored by RT-PCR after transfection. Approximately $86 \%$ and $40-4$ 5\% silencing of GLI1 transcript was achieved in Daoy and U87MG cell lines respectively (Figures 2A-B).

Silencing of GLI1 resulted in a 50\% and $60 \%$ decrease in PTCH1 expression in Daoy and U87MG cell lines respectively (Figures 2C-D). In contrast, Cyclin D2 showed a $17 \%$ decrease in Daoy and 113\% increase in U87MG cells (Figures 2E-F). Plakoglobin expression was decreased by $30 \%$ in Daoy cells and increased by $125 \%$ in U87MG cells (Figures 2G-H). PAX6 expression was decreased by $35 \%$ in Daoy cells and increased by $100 \%$ in U87MG cells (Figures 2I-J), and NKX2.2 was decreased by $50 \%$ in Daoy cells and unaltered in U87MG cells (Figures $2 \mathrm{~K}-\mathrm{L}$ ). All changes listed were specific to GLII silenced cells and cells transfected with scrambled siRNA or untransfected cells did not show similar trends.

\section{PTCH1}

siRNA-mediated silencing of GLI1 resulted in an $86 \%$ decrease in GLI1 transcript and a 50\% decrease in PTCH1 transcript in the Daoy cell line compared with scrambled siRNA and untransfected Daoy cell lines.

We subsequently sought to determine the pattern of PTCH1 transcript expression in 6 medulloblastoma cell lines and 14 primary medulloblastoma samples and observed that $50 \%$ of the cell lines and tumor samples showed high expression of PTCH1 [26] (Figure 3A). However, we were unable to find any significant correlation between GLI1 and PTCH1 expression in the cell lines and tumor samples $(\mathrm{p}=0.07)$.

We also analyzed 27 astrocytoma tumor samples for co-expression of PTCH1 and GLI1. We observed a mixed expression pattern amongst the low-grade to high-grade samples. Few of the high-grade tumors expressed high levels of PTCH1 in the absence of GLI1 expression and few of them showed high expression in the presence of GLI1 expression. Overall, the pattern of
PTCH1 expression was low amongst all samples, despite varying levels of GLI1 expression (Figure 3B).

\section{Cyclin D2}

Silencing GLI1 in the Daoy cell line resulted in a $17 \%$ decrease in Cyclin D2 expression compared with scrambled siRNA and untransfected cell lines (Figure 2E). We evaluated Cyclin D2 expression in 6 cell lines and 14 medulloblastoma tumor samples and observed that most of them showed high expression levels of Cyclin D2, with the exception of cell line SK-PN-DW (Figure 4A) and one tumor sample (Figure 3C, Table 2). We did not observe any significant correlation between GLI1 and Cyclin D2 expression.

Six astrocytoma cell lines (U87MG, A172, LN405, SW1783, T98G and SW1783) expressed Cyclin D2 at very low levels, and two cell lines (CCF-STTG-1 and GOS-3) did not express Cyclin D2 compared to normal adult brain tissue $(\mathrm{p}=0.006)$ (Figure $4 \mathrm{~B})$. Fourteen high grade astrocytomas (grades III and IV) were assessed for Cyclin D2 and GLI1 expression: only 2 glioblastomas (grade IV) co-expressed Cyclin D2 and GLI1 at high levels (Figure 3D). Low levels of GLI1 were found to be associated with high expression levels of Cyclin D2 in the glioblastoma samples $(\mathrm{p}=0.007)$.

\section{Plakoglobin}

We observed a $30 \%$ decrease in expression of Plakoglobin in upon silencing of GLI1 in Daoy transfected cells (Figure 2G). Most of the 6 cell lines and 14 primary tumor samples analyzed showed high expression levels of Plakoglobin compared to normal brain tissue (Figure $4 C)$. Additionally, we detected an inverse correlation in levels of expression of GLI1 and Plakoglobin in primary medulloblastoma samples, with the exception of two tumors (Figure 3E). However, this correlation was not significant.

Among the 8 astrocytic cell lines, 5 (U87MG, A172, LN405, SW1783 and T98G) showed low levels of Plakoglobin expression, and the remaining 3 (SW1088, CCFSTTG-1 and GOS3) expressed Plakoglobin at levels higher than seen in normal adult brain tissue $(\mathrm{p}=0.02)$ (Figure 4D). A majority of the astrocytic tumor samples (24/27, 89\%) expressed Plakoglobin at low levels compared to normal brain tissue (Figure 3F). There was a distinct pattern of Plakoglobin expression in astrocytic tumor samples: low-grade (AII) samples did not express Plakoglobin and few high-grade samples highly expressed Plakoglobin in the absence of GLI1 mRNA expression. The remaining samples expressed Plakoglobin at low levels in the presence of GLI1.

\section{PAX6}

Our results show a $35 \%$ reduction in expression of PAX6 gene upon GLI1 silencing in the Daoy cell line compared with scrambled and untransfected controls (Figure 2I). In our study, we monitored the expression 


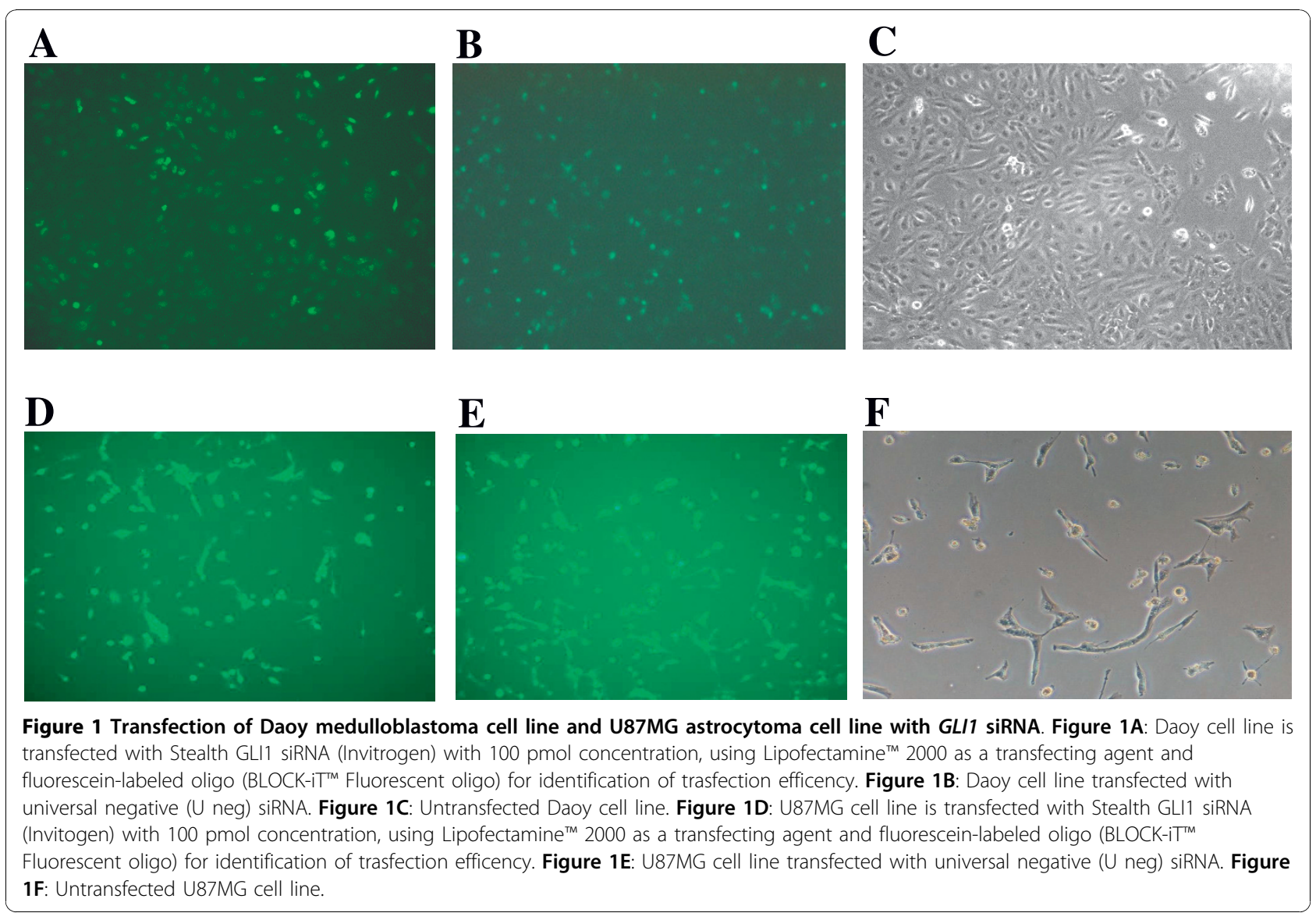

of the PAX6 gene in 6 medulloblastoma cell lines and 14 medulloblastoma primary tumor samples: a majority of the cell lines showed moderate expression levels of PAX6 with the exception of the PFSK-1 and D283 cell lines $(p=0.015)$ (Figure 4E). Similarly, most of the primary tumor samples showed high levels of $P A X 6$ expression compared to GLI1 in the same samples (Figure 3G).

Most of the astrocytic cell lines (A172, SW1783, T98G, SW1088, CCF-STTG-1 and GOS-3) expressed $P A X 6$ at low levels, and only 2 (U87MG and LN405) expressed PAX6 at high levels compared to normal adult brain tissues $(\mathrm{p}=0.006)$ (Figure $4 \mathrm{~F})$. Amongst the primary tumor samples, 20/27 (74\%) samples showed low expression of PAX6 as compared to normal adult brain tissue (Figure $3 \mathrm{H}$ ). Interestingly, most of the astrocytic tumor samples showed low expression levels of $P A X 6$ even though GLI1 was expressed at high levels.

NKX2.2

Silencing of GLI1 resulted in a decrease in NKX2.2 by $50 \%$ in the Daoy cell line compared with scrambled siRNA transfected and untransfected cells (Figure $2 \mathrm{~K}$ ). Expression of NKX2.2 was low in 2 cell lines (Daoy and TE671c2), high in only one (SK-PN-DW) $(\mathrm{p}=0.015)$ and was not expressed in the remaining 3 (TE671,
PFSK-1 and D283) (Figure 4G). Primary medulloblastomas also showed a similar pattern of low expression of $N K X 2.2$ and this correlated with high expression levels of PAX6 (Figures 3G-I).

Six astrocytic cell lines (A172, LN405, T98G, SW1088, CCF-STTG-1 and GOS-3) showed very low expression of NKX2.2, and the remaining 2 cell lines (U87MG and SW178) did not express it at all, compared with expression levels in normal adult brain tissue $(\mathrm{p}=0.0001)$ (Figure $4 \mathrm{H}$ ). Out of the 27 astrocytic tumor samples, 20 (74\%) showed low expression of NKX2.2 compared with normal adult brain tissue $(\mathrm{p}<0.001)$ (Figure 3J). Amongst the samples, low-grade tumors did not express $N K X 2.2$; however, few of the high-grade samples showed very high expression levels of NKX2.2 and low expression of GLI1. Overall, most samples expressed NKX2.2 at low levels while expressing GLI1 to a high degree (Figure 3J).

\section{No correlation between GLI1 and Cyclin D2 protein expression}

GLI1 protein was expressed in most astrocytic cell lines with the exception of two (U87MG and A172) (Figure $5 \mathrm{~A})$. However, very low expression of Cyclin D2 protein was observed in the following seven cell lines: U87MG, 

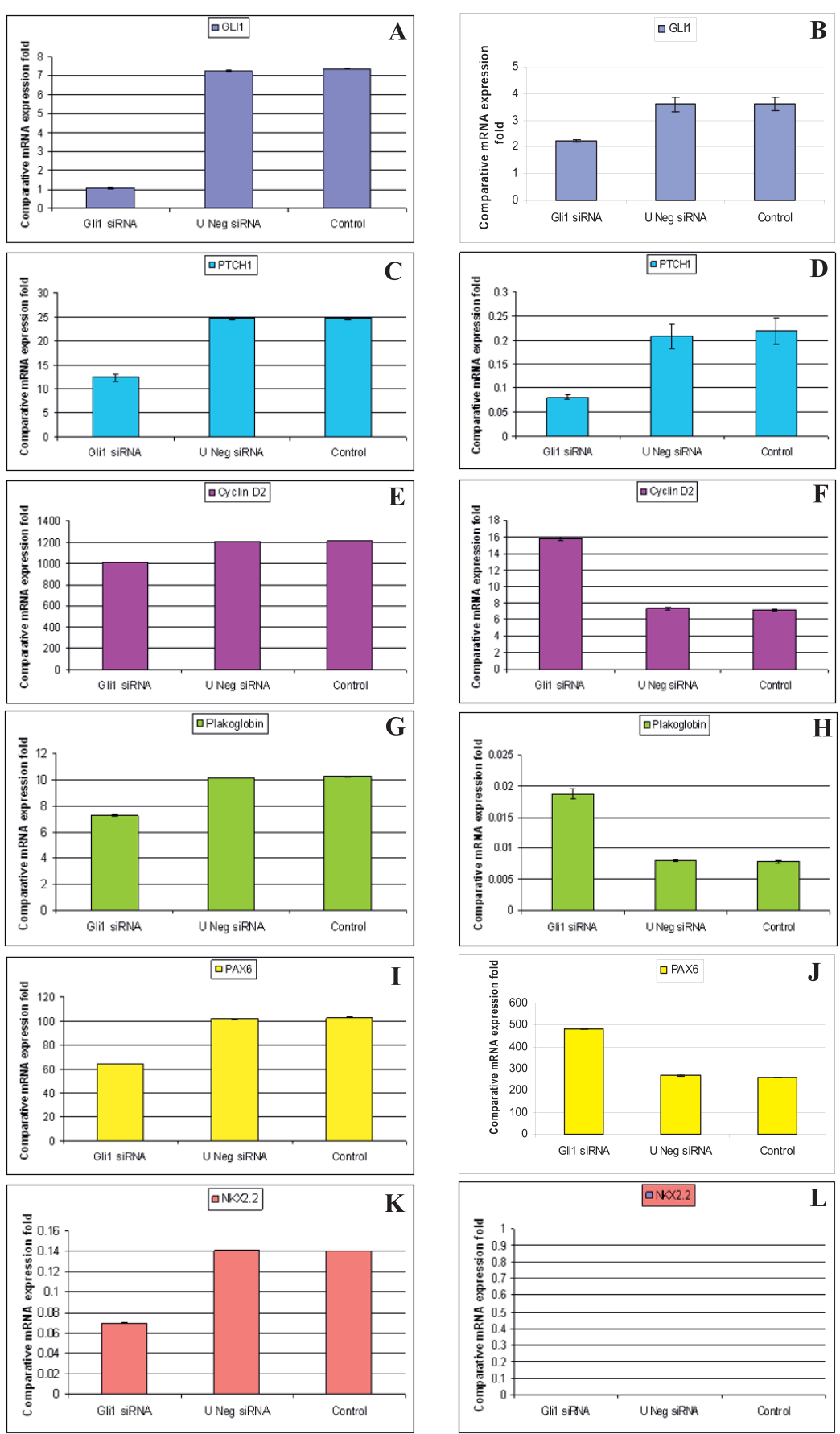

Figure 2 qRT-PCR comparative expression of GLI1, PTCH1, Cyclin D2, Plakoglobin, PAX6 and NKX2.2 genes in GLI1 knock-down, negative and untransfected Daoy medulloblastoma cell line and U87MG astrocytoma cell line. After $72 \mathrm{~h}$ of siRNA-mediated transfection, GL/1 showed 83\% decrease in expression in Daoy cell line (Figure 2A) and 40-45\% decrease in expression in U87MG cell line (Figure 2B) compared to universal negative siRNA and untransfected cell lines. The siRNA-mediated GL/1 knock-down cell lines Daoy and U87MG showed 50\% (Figure 2C) and 60\% (Figure 2D) decrease in expression of PTCH1 respectively. The GL/1 knock-down cell lines (Daoy and U87MG) showed 17\% decrease (Figure 2E) and 113\% increase (Figure 2F) in expression of Cyclin D2 respectively. The cell lines Daoy and U87MG showed 30\% decrease (Figure $\mathbf{2 G}$ ) and $\mathbf{1 2 5 \%}$ increase (Figure $\mathbf{2 H}$ ) in expression of Plakoglobin respectively, compared to universal negative siRNA and untransfected cell lines. The knock-down cell lines (Daoy and U87MG) showed 35\% decrease (Figure 2I) and 100\% increase (Figure 2J) in expression of PAX6 respectively, compared to universal negative and untransfected cell lines. We further checked the expression of NKX2.2 in these two GLI1 knock-down cell lines (Daoy and U87MG) and found 50\% decrease (Figure 2K) and not any changes in the expression of NKX2.2 (Figure $\mathbf{2 L}$ ) respectively, compared to universal negative and untransfected cell lines. 


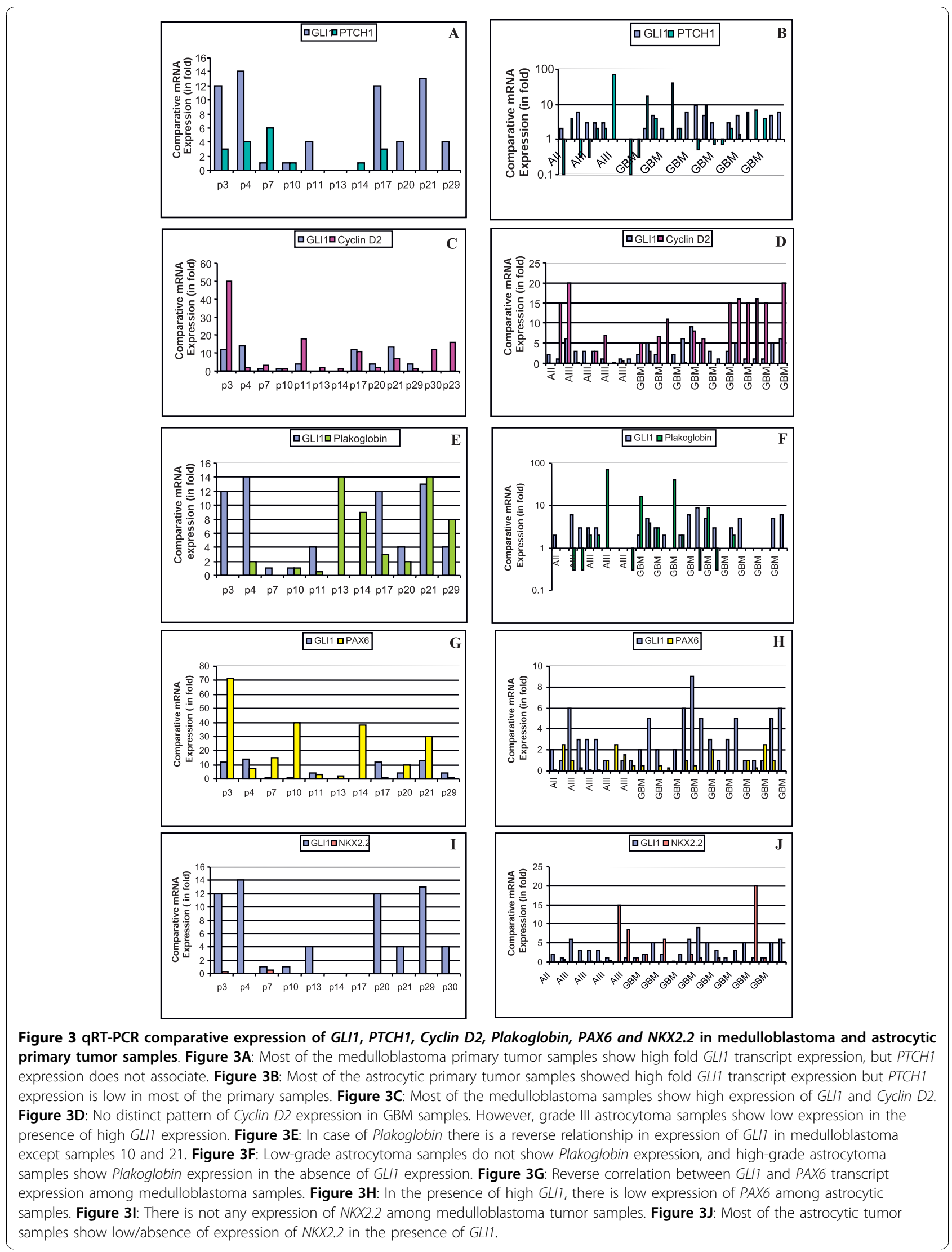



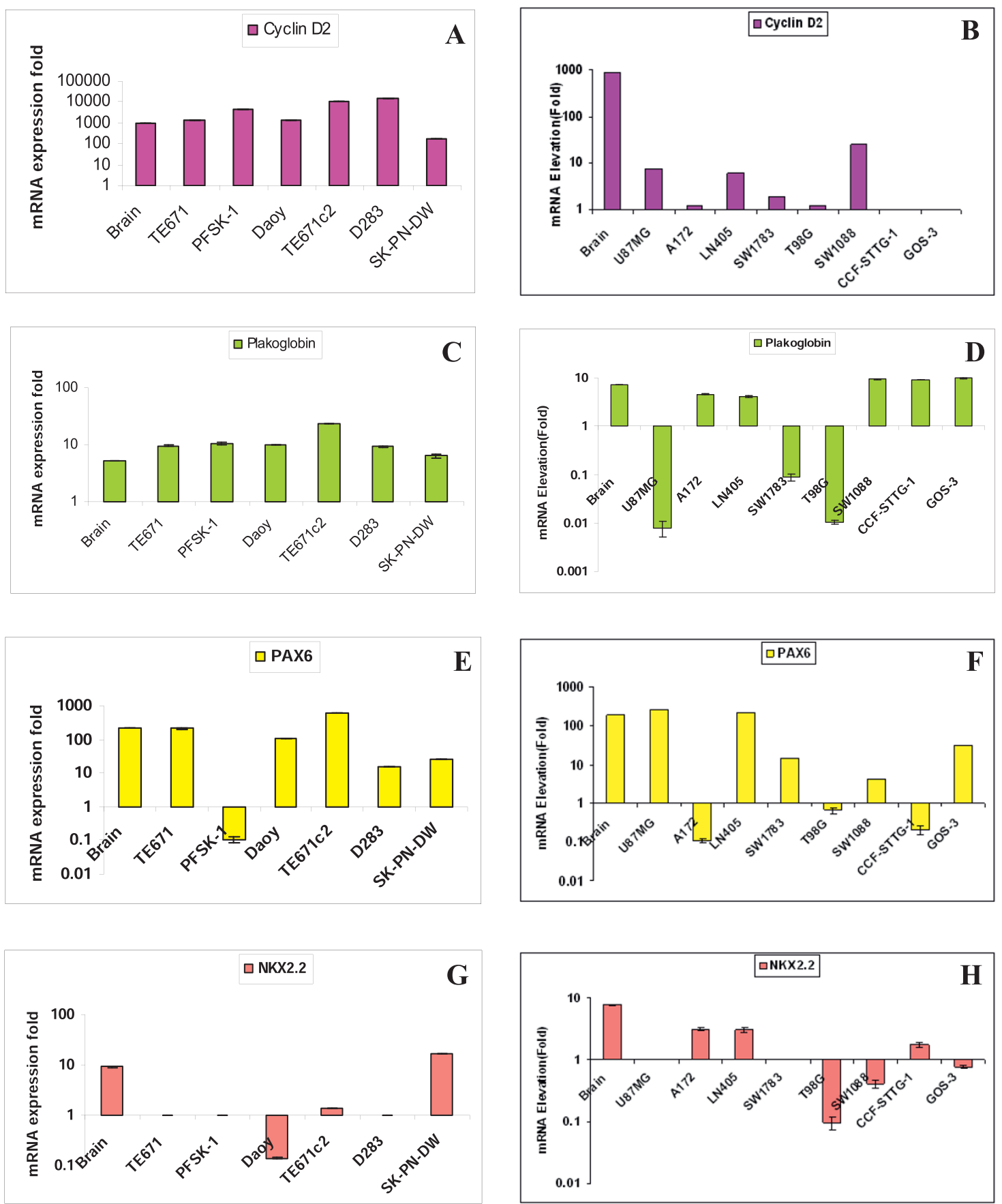

Figure 4 qRT-PCR comparative expression of Cyclin D2, Plakoglobin, PAX6 and NKX2.2 in medulloblastoma and astrocytoma cell lines (for GLI1 and PTCH1, please check reference [26]). Figure 4A: All 6 medulloblastoma cell lines show equal expression of Cyclin D2 as compared to normal adult brain tissue; interestingly normal brain itself shows high expression of Cyclin D2. Figure 4B: Four astrocytic cell lines show very low expression and the remaining 4 cell lines show no expression of Cyclin D2 transcript as compared to normal adult brain tissue ( $p$ $<0.001)$. Figure 4C: All 6 medulloblastoma cell lines show high fold expression of Plakoglobin compared to normal adult brain tissue. Figure 4D: Five astrocytic cell lines show low expression of Plakoglobin transcript compared to normal brain tissue. Figure 4E: Only one medulloblastoma cell line, TE671c2, shows high expression fold of PAX6 as compared to normal adult brain tissue. Figure 4F: Most of the astrocytoma cell lines, except U87MG and LN405, show low expression of PAX6 transcript compared to normal brain tissue. Figure 4G: Most of the medulloblastoma cell lines show no/low expression of NKX2.2 except SK-PN-DW, as compared to normal adult brain tissue. Figure $\mathbf{4 H}$ : All 8 astrocytic cell lines show no/low expression of NKX2.2 transcript compared to normal brain tissue. SYBER Green dye was used for the quantification of CDNA by qRT-PCR. Comparative expression of samples was plotted on Y-axis with Log10. 
A172, LN405, SW1088, T98G, CCF-STTG-1 and GOS3; moreover, there was no expression of Cyclin D2 in one cell line (SW1783) (Figure 5D). Most of the primary tumor samples showed high expression levels of the GLI1 protein (Figures 5B-C) but these samples did not express Cyclin D2 (Figures 5E-F).

\section{Cyclin D2 and PTCH1 epigenetics}

We did not observe any changes in the pattern of Cyclin D2 expression upon treatment of the medulloblastoma cell lines with 5-Aza-2'-deoxycytidine and TSA. However, treatment with these compounds resulted in the onset of Cyclin D2 expression, assessed by both RT-PCR and qRT-PCR in five astrocytoma cell lines that did not initially express Cyclin D2 (A172, SW1783, T98G, CCFSTTG-1 and GOS-3) (Figures 6A-B) (Table 3).

The increase in Cyclin D2 mRNA in these cell lines was statistically significant $(\mathrm{p}=0.0014)$ (Figure 6C).

Amongst the 6 medulloblastoma cell lines assayed using the MCA-Meth method, only PFSK-1 and SK-PNDW showed a hemi-methylation melting curve (Figure 7B). However, hypermethylation was revealed in all cell lines by MSP (Figure 7E) (Table 1). Methylation associated with low Cyclin D2 expression was evident only in the SK-PN-DW cell line (Table 1). In medulloblastoma samples, no methylation was detected by MCAMeth primers (Figure 7A), even though some tumors expressed Cyclin D2 at low levels. However, MSP showed promoter hypermethylation which was associated with the lack of mRNA expression or low expression in tumor samples (Figure 7G) (Table 2).

In astrocytomas, methylation analysis by MCA-Meth and MSP-PCR methods was performed on 8 cell lines. Five of the cell lines did not express Cyclin D2, and 3 of these (U87MG, T98G, and GOS-3) showed methylation/ partial methylation by MCA-Meth analysis (Figures 7BC). However, the remaining 2 cell lines did not express Cyclin D2, nor did they show any methylation curves by the MCA-Meth method (Figure 7A). However, MSP identified methylation/partial methylation in $6 / 8$ cell lines (Figure 7F). U87MG, which showed partial methylation also expressed Cyclin D2, albeit at lower levels compared with normal adult brain tissue (Table 3). We performed the same assays to evaluate Cyclin D2 promoter methylation in primary astrocytoma samples and found that the Cyclin D2 promoter was methylated/partially methylated in 14/44 (32\%) of the tumors (Figures 7B-D) (Table 4). MSP-PCR identified 12/44 (27\%) of the samples as methylated at the Cyclin D2 promoter (Figure $7 \mathrm{H}$ ). However, only 4 astrocytic tumor samples (3, 13, 18 and 24) demonstrated Cyclin D2 promoter hypermethylation by both methods (Table 4).

We also compared the melting curves (using the MCA-Meth method) of the Cyclin D2 promoter region before and after treatment with 5-Aza-2'-dexoycytidine and TSA and found a shift in the melting curve from the methylated promoter $\left(81^{\circ} \mathrm{C}\right)$ to the unmethylated promoter $\left(78^{\circ} \mathrm{C}\right)$ (Figures $\left.8 \mathrm{C}-\mathrm{D}\right)$.

Our PTCH1 methylation results among the 6 medulloblastoma cell lines identified a methylated peak in only one cell line, D283 (Figure 8A) (Table 1). This was associated with low levels of PTCH1 expression. Despite low expression, we were unable to observe methylated/ unmethylated peaks in 2 other cell lines (TE671c2 and SK-PN-DW) (Figure 8B). Among medulloblastomas, 2/8 tumor samples showed methylated melting peaks, which were associated with low expression (Table 2). The $P T C H 1$ promoter region was methylated as assayed by the MCA-MSP method in only $1 / 8$ astrocytic cell lines (CCF-STTG-1 (Figure 8A) and 3/44 (7\%) primary tumor samples. Interestingly, the cell lines and samples showing PTCH1 promoter methylation were either glioblastomas (grade IV astrocytoma) or anaplastic astrocytomas (AIII) (Tables 3 and 4).

\section{Discussion}

In the course of our studies, we sought to understand the regulation of certain downstream target genes of the Shh pathway, including PTCH1, Cyclin D2, Plakoglobin, NKX2.2, and PAX6, in a panel of medulloblastoma and astrocytoma cell lines and tumors. We attempted to explore any putative regulation of these genes by the major transcription factor involved in Shh signaling, GLI1, as well as at the epigenetic level.

\section{PTCH1}

After siRNA-mediated GLI1 silencing in Daoy and U87MG cell lines, expression of PTCH1 decreased, compared with scrambled siRNA-transfected and untransfected cell lines, which may suggest positive regulation of PTCH1 by GLI1 in medulloblastomas and astrocytomas. We further assessed PTCH1 expression in cell lines and samples of both tumor types, and observed that $50 \%$ of the samples showed high expression levels of PTCH1. This "mixed-pattern" of PTCH1 expression amongst samples suggests that there may be GLI1 independent regulatory mechanisms, both at the genetic and/or epigenetic level, influencing PTCH1 expression. It is important to note that reports have shown PTCH1 promoter hypermethylation in several cancers, including medulloblastomas [31,32].

Our previous study demonstrated a correlation between high expression levels of GLI1 and PTCH1 [26]. However, some of the cell lines and samples expressed low levels of PTCH1 in spite of high GLI1 levels, which may be suggestive of the fact that those cells are in a different phase of GLI1/PTCH1 interplay. As a putative explanation, high expression of GLI1 


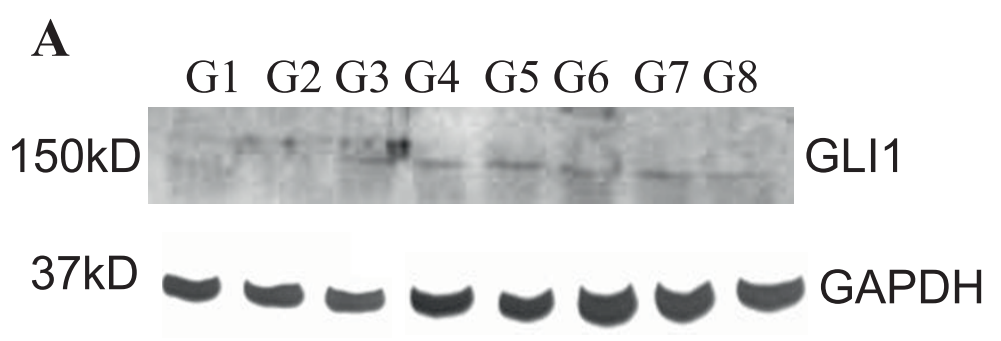

B

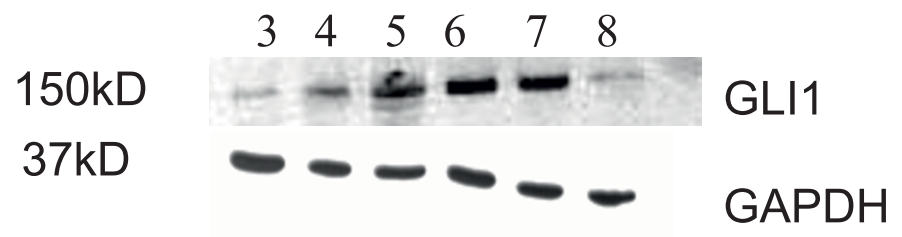

C

$150 \mathrm{kD}$

91011202122

$37 \mathrm{kD}$

GLI1

D

\begin{tabular}{|c|c|c|c|c|c|c|c|c|c|}
\hline & G1 & G2 & G3 & G4 & G5 & G6 & G7 & G8 & Cyclin D2 \\
\hline
\end{tabular}

$\mathbf{E}$

$34 \mathrm{kD}$

$\begin{array}{llllll}3 & 4 & 5 & 6 & 7 & 8\end{array}$

$37 \mathrm{kD}$

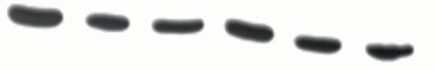

GAPDH

F $\quad 9 \quad 10 \quad 11202122$

$34 \mathrm{kD}$

Cyclin D2

$37 \mathrm{kD}$

Cyclin D2

Figure 5 Protein expression of GLI1 and Cyclin D2 in astrocytic cell lines and tumor samples. Figure 5A: The first two cell lines (G1: U87MG and G2: A172) do not show very distinct bands, but the remaining 6 cell lines (G3: LN405, G4: SW1783, G5: T98G, G6: SW1088, G7: CCFSTTG-1 and G8: GOS-3) show distinct bands of GLI1 protein. Figures 5B and Figure 5C show GLI1 protein expression in astrocytic tumor samples 3-8 and 9, 10, 11, 20, 21 and 22. Figure 5D: Low protein expression of Cyclin D2 in astrocytic cell lines G1: U87MG, G2: A172, G3: LN405, G5: T98G, G6: SW1088, G7: CCF-STTG-1 and G8: GOS-3. Only one cell line (G4: SW1783) does not express Cyclin D2 protein. Figures 5E and Figure 5F: Cyclin D2 protein expression is not shown in astrocytic tumor samples (3-8 and 9, 10, 11, 20, 21 and 22). 
$\mathbf{A}$

A172 SW1783 T98G CCF-STTG GOS-3
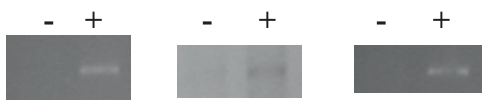

$-+$

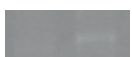

$-\quad+$
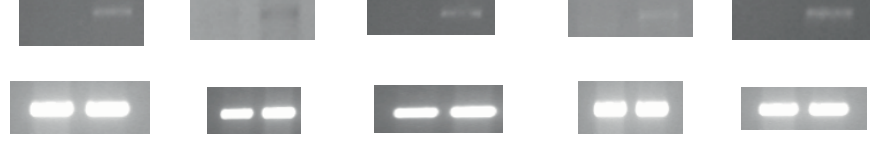

TFR

B

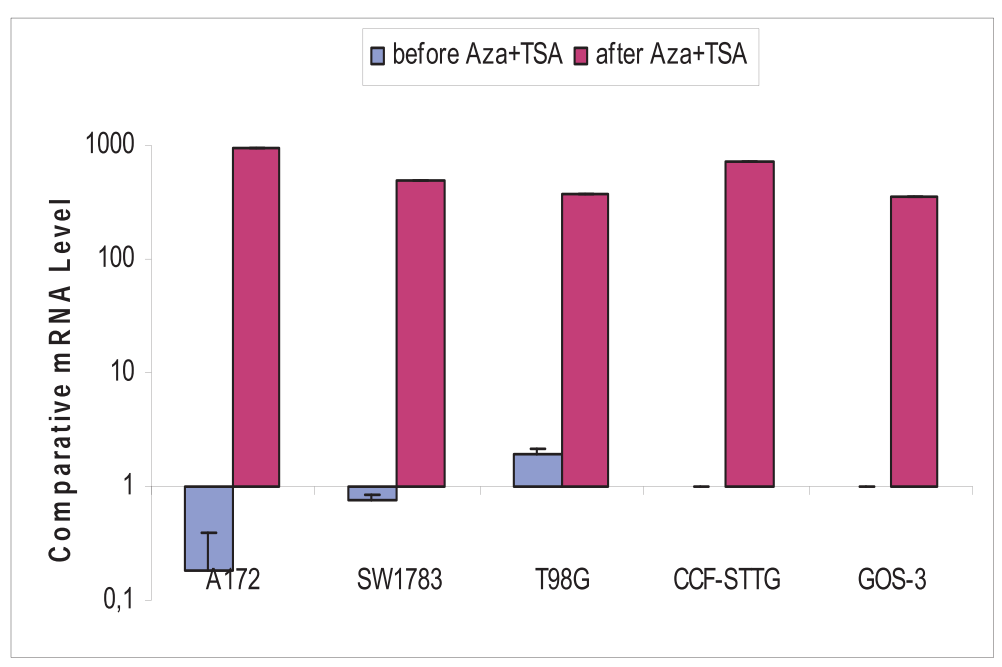

C

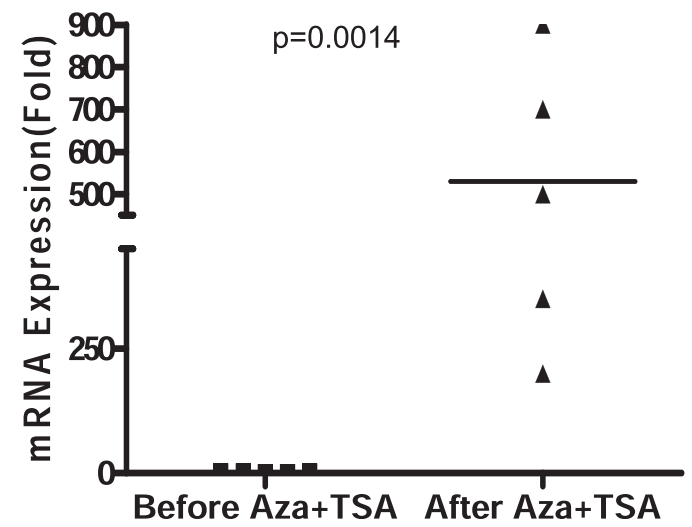

Figure 6 Reversal of Cyclin D2 expression after treatment with demethylating agent 5-Aza-2'-deoxycytidine and TSA. Figure 6A: All 5 cell lines (A172, SW1783, T98G, CCF and GOS-3) show reversal in the expression of Cyclin D2 by RT-PCR. -: before treatment; +: after treatment. Figure 6B: Reversal of expression of Cyclin D2 transcript in the 5 cell lines after the treatment with 5-Aza-2'-dC and TSA, by qRT-PCR. Figure 6C: Comparative fold expression of Cyclin D2 after the treatment with 5-Aza-2'-dC and TSA. Some astrocytic cell lines even showed 200 fold increase in Cyclin D2 expression ( $p=0.0014)$. 

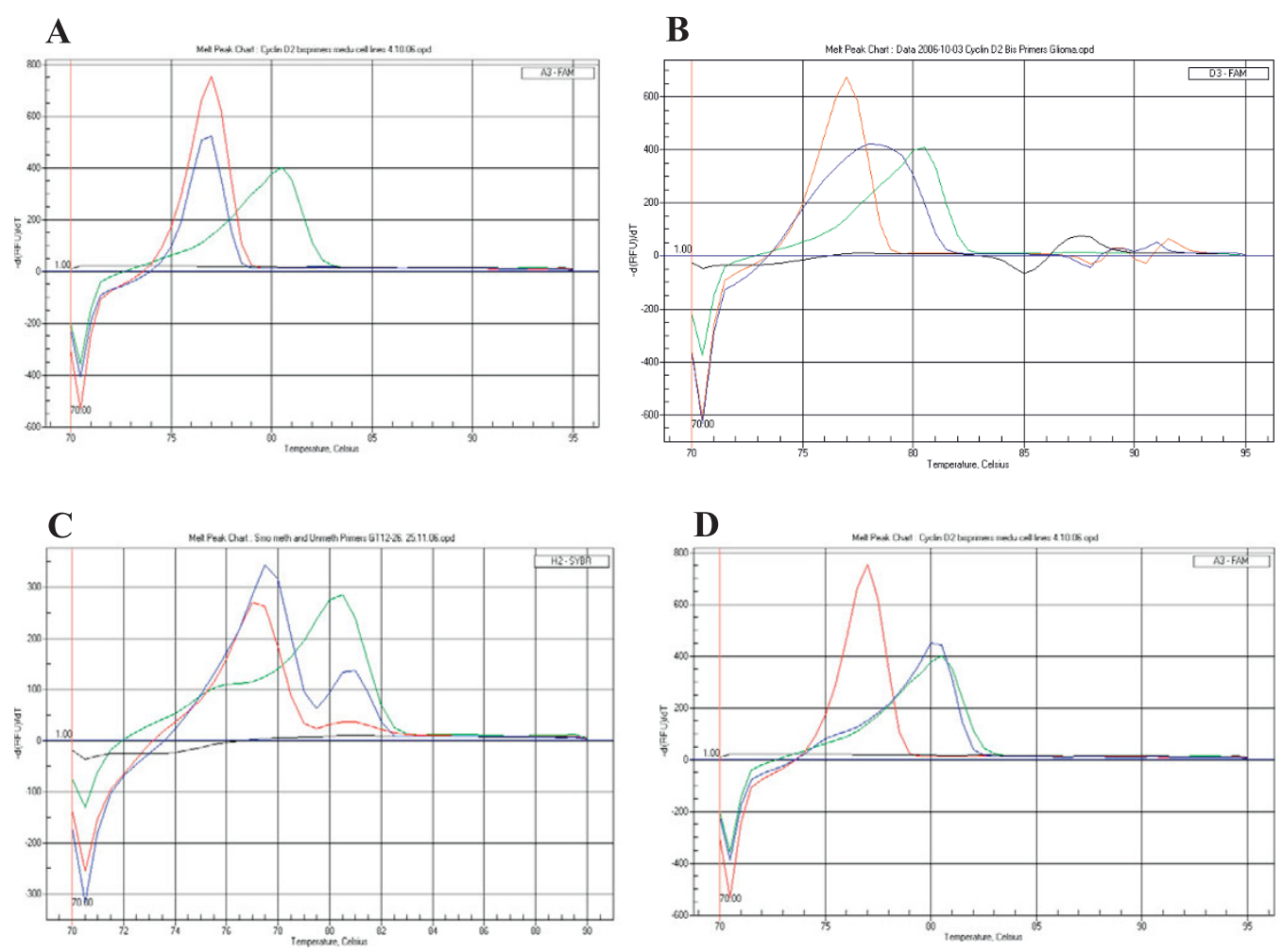

$\underline{\text { TE671 }} \underline{\text { PFSK-1 Daoy }} \underline{\text { TE671c2 }} \underline{\text { D283 }}$ SK-PN-DW

\section{$\mathrm{U}$ M}

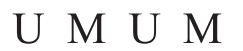

$\mathrm{U} \mathrm{M}$

$\mathrm{U} M$

$\mathrm{U} M$

$\mathbf{E}$

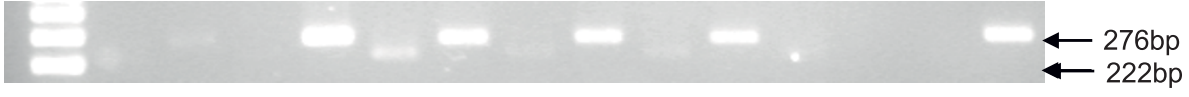

$\underline{\mathrm{U} 87} \underline{\mathrm{A172}} \underline{\mathrm{LN} 405}$

$\underline{\text { SW1783 T98G SW108 CCF-ST GOS3 }}$

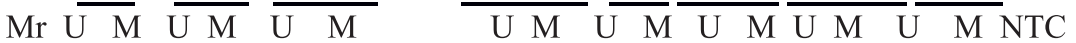

$\mathbf{F}$
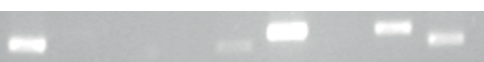

\section{$\longleftarrow 276 \mathrm{bp}$}

\section{$\underline{3} \quad \underline{4} \quad \underline{7} \quad \underline{10} \quad \underline{11} \quad \underline{13} \quad \underline{14} \quad \underline{17} \quad \underline{20}$ \\ Mr UM UM UM UM UM UM UM UM UM}

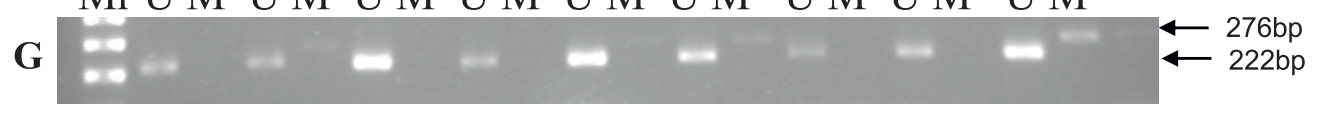

\section{$\underline{21} \quad \underline{22} \quad \underline{23} \quad \underline{24} \quad \underline{25} \quad \underline{26} \quad \underline{29} \quad \underline{30} \quad \underline{31}$}

$M \quad \cup M \frac{21}{U M} \cup M \quad \frac{23}{U M} \cup \frac{25}{U M} \cup M \frac{29}{U M} \cup M N T C$

\section{$\mathbf{H}$}

$$
\text { - }
$$

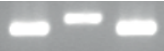

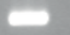

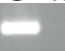

$0-2 M$

Figure 7 Promoter methylation analysis of Cyclin D2. 7A-D: Medulloblastoma and astrocytoma cell lines unmethylation melting curve pattern (Figure 7A); hemi-methylation curve pattern (Figure 7B); partial methylation curve pattern (Figure 7C); and complete methylation curve (Figure 7D) of Cyclin D2 promoter shown by the MCA-Meth method. Figure 7E: Cyclin D2 promoter methylation in medulloblastoma cell lines by MSP. Three cell lines (Daoy, TE671c2 and D283) show hemimethylation (U+M) and the remaining three cell lines (TE671, PFSK-1 and SKPN-DW) show complete methylation (M). Unmethylated and methylated PCR product bands are 222 and 276 bp, respectively. Figure 7F: Among astrocytic cell lines three of them (U87MG, SW1783 and GOS-3) show hemi-methylation; 2 show complete methylation (M) (T98G and CCF-STTG1); and the other 2 (A172 and LN405) show no methylation (U). Figure 7G: Promoter methylation analysis of medulloblastoma samples. Figure 7H: Promoter methylation analysis of astrocytoma samples. 

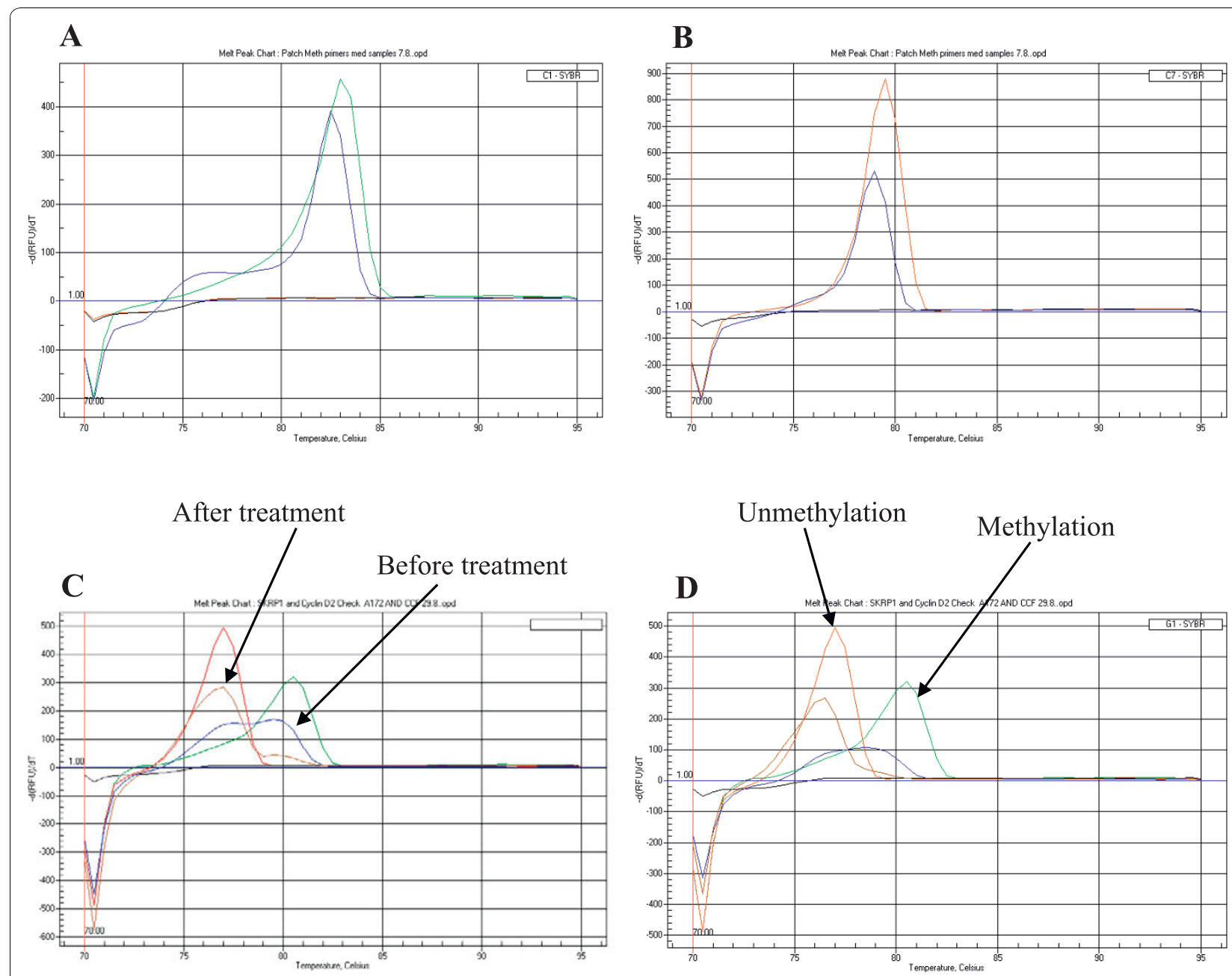

Figure 8 PTCH1 promoter methylation analysis. Figure 8A: PTCH1 promoter methylation curve by MCA-MSP. Figure 8B: PTCH1 promoter unmethylation curve. Melting curve shown by MCA-Meth. Figure $\mathbf{8 C}-\mathbf{D}$. Reversal of methylation melting curve after the treatment with 5-Aza-2'$\mathrm{dC}$ and TSA in CCF-STTG-1 (Figure 8C) and GOS-3 (Figure 8D) astrocytic cell lines.

associated with low expression of PTCH1 may indicate a switch-on of Shh signaling (phase 1), trying to exit from a previous resting point -phase 0- (GLI1 low expression/ PTCH1 low expression), to advance towards phase 2, a GLI1 high expression/PTCH1 high expression phase characterized by PTCH1 demethylation and expression, to finally reach phase 3 (GLI1 low expression/PTCH1 high expression), equivalent to switching off the Shh signaling process.

For epigenetic studies, we chose the distal region $1 \mathrm{C}$ of the PTCH1 promoter [29], and found only $1 / 6$ of the medulloblastoma cell lines bearing methylation at the promoter, although two other cell lines also showed low expression levels of PTCH1. Among the medulloblastoma samples, $2 / 8$ (25\%) showed methylation together with lack of PTCH1expression. Several reports have illuminated aspects of $\mathrm{PTCH} 1$ epigenetic regulation: no methylation has been reported in the proximal promoter region $1 \mathrm{~B}$ of the $P T C H 1$ promoter in primary medulloblastomas, suggesting the possibility of methylation of its distal region, $1 \mathrm{C}$ [31]; a knockout mouse tumor model has documented changes in PTCH1 expression after treatment with demethylating agents [32]. To follow up on these reports, we decided to further analyze the hypermethylation of $P T C H 1$ proximal promoter region, $1 \mathrm{~B}$. Our results identified methylation of the promoter region in only $1 / 8$ astrocytoma cell lines and 3/27 $(11 \%)$ astrocytic tumor samples of high histologic grades.

The PTCH1 promoter was hypermethylated in mice tumor models as demonstrated by changes in PTCH1 expression after treatment with demethylating agents [32]. However, another study suggests that there is no methylation of the proximal region of the $P T C H 1$ promoter, $P T C H 1-1 B$, although methylation may be concentrated at the distal end of the promoter, or even 
alternative exon variants, including $P T C H 1-1 B$ and PTCH1-1C [29].

\section{Cyclin D2}

To determine whether GLI1 regulates Cyclin D2 in medulloblastomas, we quantified levels of Cyclin D2 transcript upon silencing of GLI1 by siRNA in the Daoy medulloblastoma cell line. We observed a decrease in Cyclin D2 expression in comparison to controls, which suggests that GLI1 may up-regulate Cyclin D2, concurring with previous reports showing similar results in GLI1 transformed epithelial cells [13]. This evidence is strengthened by the presence of the GLI1 consensus binding sequence on the Cyclin D2 promoter [13]. To complete this study, we determined the expression of Cyclin D2 in 6 medulloblastoma cell lines and 14 tumor samples, and overall, we observed high expression levels of Cyclin D2 that correlated with high levels of GLI1 expression. These results indicate that Cyclin D2 may be positively regulated by GLI1 in medulloblastomas.

GLI1 silencing in the astrocytic cell line U87MG led to increased Cyclin D2 expression in comparison with controls transfected with scrambled siRNA and untransfected cells. Our results suggest that GLI1 does not upregulate Cyclin D2. These results do not concur with a previous report showing up-regulation of Cyclin D2 in a GLI1 transformed epithelial cell line [13]. This discrepancy suggests there may be two regulatory pathways: first, the differential regulatory action of the Shh signal (it may vary in different tissue types); and second, the dual nature of Cyclin D2, behaving at times as an oncogene and other times as a tumor suppressor gene [33].

Cyclin D2 expression was either low or absent in 8 astrocytic cell lines in comparison with normal brain tissue, although we detected expression of Cyclin D2 protein in all these cell lines, with the exception of SW1044. However, even protein expression was very low in comparison with the housekeeping gene GAPDH, used as a positive internal control. We detected low expression levels of Cyclin D2 transcript in U87MG, A172, LN405, T98G and SW1088 cell lines, which may correlate with low protein expression. Paradoxically, two astrocytic cell lines (CCF-STTG-1 and GOS-3) did not appear to express Cyclin D2 transcript, however, low levels of protein expression was detected. This suggests two possibilities: First, early degradation of Cyclin D2 mRNA due to a short half-life, and second, the possibility of differential splicing. We failed to detect expression of Cyclin D2 protein in any of the tumor samples.

Exploration of epigenetic regulation of Cyclin D2 in medulloblastomas and astrocytomas was motivated by previous studies which had revealed Cyclin D2 silencing in cancers such as breast [34], lung [35], and prostate [36], due to promoter hypermethylation.
Our study revealed, to a certain extent, hypermethylation of the Cyclin D2 promoter, although methylation did not fully correlate with silencing of expression in medulloblastoma cell lines. Interestingly, the methylation of the promoter in primary tumor samples was associated with low or no expression of Cyclin D2.

We treated astrocytic cell lines that did not express Cyclin D2 with the demethylating drug 5-Aza-2'-deoxycytidine and the HDAC inhibitor TSA. The combination of these two drugs improves epigenetic modulation [37]. After $72 \mathrm{~h}$ of treatment, we were able to observe Cyclin $D 2$ expression in these cell lines $(\mathrm{p}=0.0014)$. Our results are contrary to another study [38] that showed high levels of Cyclin D2 expression in the astrocytic cell lines, U87MG and T98G, and a decrease in Cyclin D2 expression after treatment with the HDAC inhibitor SAHA. Our results suggest that the demethylating agent rather than TSA, is responsible for Cyclin D2 re-expression. However, when we treated these two cell lines with only 5-Aza-2'-deoxycytidine, we observed little to no expression of Cyclin D2. However, after 5-Aza-2'deoxycytidine and TSA treatment, there was an increase in expression of Cyclin D2 in T98G, but not in U87MG cell line (accompanied by low expression levels of the Cyclin D2 protein).

Despite hemi-methylation of the Cyclin D2 promoter in U87MG cells, there was no change in Cyclin D2 expression after treatment. We assessed the hypermethylation status of the Cyclin D2 promoter in 8 cell lines and 44 astrocytic tumors by studying two putative CpG islands. SW1783 and CCF-STTG-1 cells appeared to be methylated by MSP but not by MCA-Meth. Neither MCA-Meth nor MSP detected methylation in two other astrocytic cell lines (LN405 and SW1088). Moreover, the A172 cell line did not show methylation or even partial methylation at the two CpG sites in spite of no Cyclin D2 expression in this cell line. Treatment with 5-Aza-2'-deoxycytidine and TSA induced expression of Cyclin D2, indicating that a third CpG island that we did not analyze may play an important role in regulating Cyclin D2 expression in this cell line. Unfortunately, we were unable to obtain any primers to assess hypermethylation at this $\mathrm{CpG}$ region. Interestingly, a GLI1 binding consensus sequence is also located at the third CpG-rich region of Cyclin D2 promoter, indicating the possibility of "patches hypermethylation" at this promoter [39] (differential methylation pattern in a promoter region which is supposed to be distributed at $\mathrm{CpG}$ rich regions).

\section{Plakloglobin}

We attempted to determine Plakoglobin expression in the Daoy medulloblastoma cell line upon GLI1 silencing. Plakoglobin expression was decreased when compared 
with control-transfected and untransfected cell lines. This indicates that GLI1 may positively regulate Plakoglobin expression. However, our results do not concur with a previous report which suggests that GLI1 downregulates Plakoglobin in GLI1 transformed epithelial cells [13]. Additionally, we assessed Plakoglobin expression in 6 medulloblastoma cell lines and 14 tumor samples. A majority of the cell lines and tumor samples displayed high expression levels of Plakoglobin, while only a few of the tumor samples showed little or no expression of Plakoglobin. Notably, one report suggests that high expression of Plakoglobin in medulloblastoma samples is considered to be of high prognostic value [40]. Therefore, our results may support high expression and up-regulation of Plakoglobin by GLI1 in medulloblastomas.

High levels of Plakoglobin expression after GLI1 silencing in the U87MG astrocytoma cell line is not indicative of positive regulation of this gene by GLI1. This result concurs with a previous study on GLI1-transformed epithelial cells [13]. We then sought to determine Plakoglobin expression in 8 astrocytic cell lines and 23 primary astrocytic tumor samples. More than $60 \%(5 / 8)$ of the cell lines and $89 \%(24 / 27)$ of the tumor samples expressed Plakoglobin at lower levels than normal adult brain tissue. Interestingly, there was a distinct pattern of Plakoglobin expression amongst astrocytic tumor samples: low-grade samples expressed Plakoglobin, while a few high-grade samples also showed high expression levels of Plakoglobin in absence of GLI1 transcript. However, the remaining samples all showed low levels of Plakoglobin expression in presence of GLI1 transcript. These results support that GLI1 does not appear to up-regulate Plakoglobin in astrocytomas.

\section{PAX6}

Silencing of GLI1 in Daoy cells indicated that GLI1 may up-regulate the expression of the homeodomain transcription factor I PAX6 in medulloblastomas. We also determined the expression of PAX6 in 6 medulloblastoma cell lines and 14 primary tumor samples and observed all cell lines with the exception of two expressed high levels of PAX6. Similarly, a majority of the primary tumor samples expressed high levels of PAX6 transcript compared to normal brain tissue. Previous studies have shown that GLI1 down-regulates $P A X 6$ gene expression during normal neuronal development $[14,41,42] . P A X 6$ is a transcription factor which regulates several genes involved in cell fate, proliferation, as well as migration of neuroectodermal precursor cells during development $[43,44]$. Interestingly, this suggests different mechanisms of Shh regulation during normal and malignant tissue development. A few studies report high expression levels of PAX6 in medulloblastoma samples [45]. Due to the multifunctional roles of this group of genes, it is entirely possible that other mechanisms regulating $P A X 6$ in medulloblastomas exist, which further need to be explored.

Subsequent to GLI1 silencing, we observed an increase in PAX6 expression in the transfected astrocytoma cell line U87MG. A majority of the cell lines displayed low levels of PAX6 despite high GLI1 expression, as was similarly seen in primary astrocytic tumor samples. Thus, GLI1 does not appear to up-regulate PAX6 expression in astrocytic tumors.

\section{NKX2.2}

GLI1 silencing suggests that GLI1 may up-regulate the homeodomain transcription factor II NKX2.2. in medulloblastomas. We failed to detect expression of $N K X 2.2$ transcript in 3 cell lines, observed low expression in 2, and high expression in only one cell line. This pattern of NKX2.2 transcript expression was recapitulated in tumor samples, and was associated with high levels of $P A X 6$ transcript in cell lines and tumors.

GLI1 silencing did not perturb NKX2.2 expression in the astrocytic cell line U87MG. A majority of astrocytic cell lines (75\%) and astrocytoma samples (70\%) showed either low or no expression of NKX2.2 compared to normal adult brain tissue. Nevertheless, a few highgrade samples expressed $N K X 2.2$ at very high levels when GLI1 was expressed at low levels. Overall, a majority of the samples displayed low levels of NKX2.2 expression in the presence of high GLII expression. Interestingly, however, reports suggest that Shh signaling up-regulates $N K X 2.2$ expression during normal neuronal development $[42,46]$. Low expression levels of NKX2.2 seen in our study, despite active Shh signaling, is suggestive of differential Shh signaling during normal development and in astrocytomas. Our study further supports a previous report [47] which shows that NKX2.2 is a direct target gene of Shh signaling, and is up-regulated during normal development.

\section{Statistical analysis}

Statistical analysis by the Fisher's test revealed significant correlations of GLI1 expression with PAX6 ( $\mathrm{p}=$ $0.015)$ and NKX2.2 ( $\mathrm{p}=0.015)$ expression in medulloblastoma cell lines. However, we did not find significant correlations in the expression of GLI1 with PTCH1, Cyclin D2 or Plakoglobin in the medulloblastoma cell lines. Similarly, in medulloblastoma primary tumor samples, only expression of $N K X 2.2$ showed significant correlation with GLI1 expression ( $\mathrm{p}=0.004)$.

On the contrary, we observed significant correlation of GLI1 expression with downstream target genes PTCH1 $(\mathrm{p}=0.07)$, Cyclin D2 $(\mathrm{p}=0.006)$, Plakoglobin $(\mathrm{p}=0.02)$, PAX6 ( $\mathrm{p}=0.006)$ and NKX.2.2 $(\mathrm{p}=0.0001)$ in 
astrocytoma cell lines. Finally, GLI1 expression correlated significantly with downstream target genes $P T C H 1$ $(\mathrm{p}=0.005)$, Cyclin D2 $(\mathrm{p}=0.04)$, Plakoglobin $(\mathrm{p}=$ $0.006)$, PAX6 $(\mathrm{p}=0.002)$ and NKX2.2 $(\mathrm{p}=0.008)$ in astrocytoma primary tumor samples.

\section{Conclusions}

We report that Cyclin D2 and PTCH1 are regulated by two mechanisms: at the transcriptional level and at the epigenetic level. GLI1 appears to up-regulate PTCH1 expression in both medulloblastomas and astrocytomas, and remaining genes tested, namely, Cyclin D2, Plakoglobin, PAX6, and NKX2.2, only in medulloblastomas. Analysis of promoter methylation suggests that epigenetic regulation of Cyclin D2 is stronger in astrocytomas than in medulloblastomas, while epigenetic regulation of PTCH1 is weak in both tumors. Based on our results, we advocate that molecules that inhibit Shh activation as well as epigenetic modulator drugs may be effectively used for the treatment of astrocytoma tumors.

\section{Abbreviations}

MSP: Methylation specific PCR; PCR: Polymerase Chain Reaction; MCA-Meth: Melting Curve Analysis-based methylation assay; MCA-MSP: Melting Curve Analysis-based Methylation Specific PCR; qMSP: Quantitative Methylation Specific PCR; qRT-PCR: Quantitative (real time) Reverse Transcribed-PCR; Shh: Sonic hedgehog; 5-Aza-2'-dC: 5'-Aza-2'-deoxycytidine; HDAC: Histone Deacetylase Inhibitor; TSA: Trichostatin A; $C_{T}$ : threshold cycle; RPMI Medium: Roswell Park Memorial Institute Medium; IMD: in vitro methylated DNA

\section{Acknowledgements}

Authors are thankful to Prof. Bengt Westermark and Dr. Chandrasekher Kanduri for critically reviewing the manuscript. M.H. Shahi was a fellow of AECI (Agencia Española de Cooperación Internacional), Madrid, Spain. J.S. Castresana thanks the Asociación Española de Pediatría, Madrid, for the VIII Premio Nutribén de Investigación Pediátrica. This research was supported in part by grants from the Departmento de Salud del Gobierno de Navarra ( 9 / 07), Caja Navarra (08/13912), and Fundación Universitaria de Navarra, Pamplona; Fondo de Investigación Sanitaria (PI081849), and Fundación Mapfre Medicina, Madrid.

\section{Author details \\ 'Brain Tumor Biology Unit-CIFA, University of Navarra School of Sciences, Pamplona, Spain. ${ }^{2}$ Department of Zoology, Aligarh Muslim University, Aligarh, India. ${ }^{3}$ Department of Biochemistry, All India Institute of Medical Sciences, New Delhi, India. ${ }^{4}$ Department of Pathology, Johns Hopkins University School of Medicine, Baltimore, MD, USA. ${ }^{5}$ Research Unit, La Paz University Hospital, Madrid, Spain. ${ }^{6}$ Department of Neurosurgery, University of Michigan Medical School, Ann Arbor, MI, USA.}

\section{Authors' contributions}

MHS carried out siRNA transfection, PCR standardization, samples processing, western blot, and Promoter Methylation studies. JSC, XF, JAR, CGE, MA and SS conceived the study, assisted in study design, statistical analysis, coordinated and helped in the draft of the manuscript. All the authors have read and approved the final version of the manuscript.

\section{Competing interests}

The authors declare that they have no competing interests.

Received: 26 March 2009 Accepted: 8 November 2010 Published: 8 November 2010
References

1. Dahmane N, Ruiz i Altaba A: Sonic hedgehog regulates the growth and patterning of the cerebellum. Development 1999, 126:3089-3100.

2. Podlasek CA, Barnett DH, Clemens JQ, Bak PM, Bushman W: Prostate development requires Sonic hedgehog expressed by the urogenital sinus epithelium. Dev Biol 1999, 209:28-39.

3. Mo R, Freer AM, Zinyk DL, Crackower MA, Michaud J, Heng HH, Chik KW, Shi XM, Tsui LC, Cheng SH, Joyner AL, Hui C: Specific and redundant functions of Gli2 and Gli3 zinc finger genes in skeletal patterning and development. Development 1997, 124:113-123.

4. Buscher D, Bosse B, Heymer J, Ruther U: Evidence for genetic control of Sonic hedgehog by Gli3 in mouse limb development. Mech Dev 1997, 62:175-182.

5. Palma V, Lim DA, Dahmane N, Sanchez P, Brionne TC, Herzberg CD, Gitton Y, Carleton A, Alvarez-Buylla A, Ruiz i Altaba A: Sonic hedgehog controls stem cell behavior in the postnatal and adult brain. Development 2005, 132:335-344.

6. Berman DM, Karhadkar SS, Hallahan AR, Pritchard Jl, Eberhart CG, Watkins DN, Chen JK, Cooper MK, Taipale J, Olson JM, Beachy PA: Medulloblastoma growth inhibition by hedgehog pathway blockade. Science 2002, 297:1559-1561.

7. Sanchez P, Clement V, Ruiz i Altaba A: Therapeutic targeting of the Hedgehog-GLI pathway in prostate cancer. Cancer Res 2005, 65:2990-2992.

8. Stecca B, Mas C, Ruiz i Altaba A: Interference with HH-GLI signaling inhibits prostate cancer. Trends Mol Med 2005, 11:199-203.

9. Zhu Y, James RM, Peter A, Lomas C, Cheung F, Harrison DJ, Bader SA: Functional Smoothened is required for expression of GLI3 in colorectal carcinoma cells. Cancer Lett 2004, 207:205-214.

10. Clement V, Sanchez P, de Tribolet N, Radovanovic I, Ruiz i Altaba A: HEDGEHOG-GLI1 signaling regulates human glioma growth, cancer stem cell self-renewal, and tumorigenicity. Curr Biol 2007, 17:165-172.

11. Preat T, Therond P, Lamour-Isnard C, Limbourg-Bouchon B, Tricoire H, Erk I, Mariol MC, Busson D: A putative serine/threonine protein kinase encoded by the segment-polarity fused gene of Drosophila. Nature 1990, 347:87-89.

12. Sisson JC, Ho KS, Suyama K, Scott MP: Costal2, a novel kinesin-related protein in the Hedgehog signaling pathway. Cell 1997, 90:235-245.

13. Yoon JW, Kita Y, Frank DJ, Majewski RR, Konicek BA, Nobrega MA, Jacob H, Walterhouse D, lannaccone P: Gene expression profiling leads to identification of GLI1-binding elements in target genes and a role for multiple downstream pathways in GLI1-induced cell transformation. $J$ Biol Chem 2002, 277:5548-5555.

14. Briscoe J, Pierani A, Jessell TM, Ericson J: A homeodomain protein code specifies progenitor cell identity and neuronal fate in the ventral neural tube. Cell 2000, 101:435-445.

15. Mayes DA, Hu Y, Teng Y, Siegel E, Wu X, Panda K, Tan F, Yung WK, Zhou YH: PAX6 suppresses the invasiveness of glioblastoma cells and the expression of the matrix metalloproteinase-2 gene. Cancer Res 2006 66:9809-9817.

16. Zhou YH, Wu X, Tan F, Shi YX, Glass T, Liu TJ, Wathen K, Hess KR, Gumin J, Lang F, Yung WK: PAX6 suppresses growth of human glioblastoma cells. J Neurooncol 2005, 71:223-229.

17. Colin C, Virard I, Baeza N, Tchoghandjian A, Fernandez C, Bouvier C, Calisti A, Tong S, Durbec P, Figarella-Branger D: Relevance of combinatorial profiles of intermediate filaments and transcription factors for glioma histogenesis. Neuropathol Appl Neurobiol 2007, 33:431-439.

18. Fogarty MP, Kessler JD, Wechsler-Reya RJ: Morphing into cancer: the role of developmental signaling pathways in brain tumor formation. $J$ Neurobiol 2005, 64:458-475.

19. Marino S: Medulloblastoma: developmental mechanisms out of control. Trends Mol Med 2005, 11:17-22.

20. Knoepfler PS, Kenney AM: Neural precursor cycling at sonic speed: N-Myc pedals, GSK-3 brakes. Cell Cycle 2006, 5:47-52.

21. Zurawel RH, Allen C, Chiappa S, Cato W, Biegel J, Cogen P, de Sauvage F, Raffel C: Analysis of PTCH/SMO/SHH pathway genes in medulloblastoma. Genes Chromosomes Cancer 2000, 27:44-51.

22. Rogister B, Ben-Hur T, Dubois-Dalcq M: From neural stem cells to myelinating oligodendrocytes. Mol Cell Neurosci 1999, 14:287-300.

23. Wechsler-Reya RJ, Scott MP: Control of neuronal precursor proliferation in the cerebellum by Sonic Hedgehog. Neuron 1999, 22:103-114. 
24. Lorente A, Mueller W, Urdangarin E, Lazcoz P, von Deimling A, Castresana JS: Detection of methylation in promoter sequences by melting curve analysis-based semiquantitative real time PCR. BMC Cancer 2008, 8:61.

25. Barber RD, Harmer DW, Coleman RA, Clark BJ: GAPDH as a housekeeping gene: analysis of GAPDH mRNA expression in a panel of 72 human tissues. Physiol Genomics 2005, 21:389-395.

26. Shahi MH, Lorente A, Castresana JS: Hedgehog signalling in medulloblastoma, glioblastoma and neuroblastoma. Oncol Rep 2008 19:681-688.

27. Brooks AR, Shiffman D, Chan CS, Brooks EE, Milner PG: Functional analysis of the human cyclin D2 and cyclin D3 promoters. J Biol Chem 1996 271:9090-9099.

28. Evron E, Umbricht CB, Korz D, Raman V, Loeb DM, Niranjan B, Buluwela L, Weitzman SA, Marks J, Sukumar S: Loss of cyclin D2 expression in the majority of breast cancers is associated with promoter hypermethylation. Cancer Res 2001, 61:2782-2787.

29. Agren $M$, Kogerman $P$, Kleman $M l$, Wessling $M$, Toftgard R: Expression of the PTCH1 tumor suppressor gene is regulated by alternative promoters and a single functional Gli-binding site. Gene 2004, 330:101-114

30. Nagao K, Toyoda M, Takeuchi-Inoue K, Fujii K, Yamada M, Miyashita T: Identification and characterization of multiple isoforms of a murine and human tumor suppressor, patched, having distinct first exons. Genomics 2005, 85:462-471.

31. Pritchard JI, Olson JM: Methylation of PTCH1, the Patched-1 gene, in a panel of primary medulloblastomas. Cancer Genet Cytogenet 2008, 180:47-50

32. Uhmann A, Ferch U, Bauer R, Tauber S, Arziman Z, Chen C, Hemmerlein B, Wojnowski L, Hahn H: A model for PTCH1/Ptch1-associated tumors comprising mutational inactivation and gene silencing. Int J Oncol 2005 27:1567-1575

33. Meyyappan M, Wong H, Hull C, Riabowol KT: Increased expression of cyclin D2 during multiple states of growth arrest in primary and established cells. Mol Cell Biol 1998, 18:3163-3172.

34. Sharma G, Mirza S, Prasad CP, Srivastava A, Gupta SD, Ralhan R: Promoter hypermethylation of p16(INK4A), p14(ARF), CyclinD2 and Slit2 in serum and tumor DNA from breast cancer patients. Life Sci 2007, 80:1873-1881.

35. Virmani A, Rathi A, Heda S, Sugio K, Lewis C, Tonk V, Takahashi T, Roth JA, Minna JD, Euhus DM, Gazdar AF: Aberrant methylation of the cyclin D2 promoter in primary small cell, nonsmall cell lung and breast cancers. Int J Cancer 2003, 107:341-345.

36. Henrique R, Costa VL, Cerveira N, Carvalho AL, Hoque MO, Ribeiro FR, Oliveira J, Teixeira MR, Sidransky D, Jeronimo C: Hypermethylation of Cyclin D2 is associated with loss of mRNA expression and tumor development in prostate cancer. J Mol Med 2006, 84:911-918.

37. Cameron EE, Bachman KE, Myohanen S, Herman JG, Baylin SB: Synergy of demethylation and histone deacetylase inhibition in the re-expression of genes silenced in cancer. Nat Genet 1999, 21:103-107.

38. Yin D, Ong JM, Hu J, Desmond JC, Kawamata N, Konda BM, Black KL, Koeffler HP: Suberoylanilide hydroxamic acid, a histone deacetylase inhibitor: effects on gene expression and growth of glioma cells in vitro and in vivo. Clin Cancer Res 2007, 13:1045-1052.

39. Hsieh CL: Stability of patch methylation and its impact in regions of transcriptional initiation and elongation. Mol Cell Biol 1997, 17:5897-5904.

40. Misaki K, Marukawa K, Hayashi Y, Fukusato T, Minamoto T, Hasegawa M, Yamashita J, Fujisawa H: Correlation of gamma-catenin expression with good prognosis in medulloblastomas. J Neurosurg 2005, 102:197-206.

41. Ericson J, Rashbass P, Schedl A, Brenner-Morton S, Kawakami A, van Heyningen V, Jessell TM, Briscoe J: Pax6 controls progenitor cell identity and neuronal fate in response to graded Shh signaling. Cell 1997 90:169-180.

42. Fuccillo $M$, Joyner $A L$, Fishell $G$ : Morphogen to mitogen: the multiple roles of hedgehog signalling in vertebrate neural development. Nat Rev Neurosci 2006, 7:772-783.

43. Walther C, Gruss P: Pax-6, a murine paired box gene, is expressed in the developing CNS. Development 1991, 113:1435-1449.

44. Strachan T, Read AP: PAX genes. Curr Opin Genet Dev 1994, 4:427-438

45. Kozmik Z, Sure U, Ruedi D, Busslinger M, Aguzzi A: Deregulated expression of PAX5 in medulloblastoma. Proc Natl Acad Sci USA 1995, 92:5709-5713.

46. Vokes SA, Ji H, McCuine S, Tenzen T, Giles S, Zhong S, Longabaugh WJ, Davidson EH, Wong WH, McMahon AP: Genomic characterization of Gli- activator targets in sonic hedgehog-mediated neural patterning. Development 2007, 134:1977-1989.

47. Briscoe J, Sussel L, Serup P, Hartigan-O'Connor D, Jessell TM, Rubenstein JL, Ericson J: Homeobox gene Nkx2.2 and specification of neuronal identity by graded Sonic hedgehog signalling. Nature 1999, 398:622-627.

\section{Pre-publication history}

The pre-publication history for this paper can be accessed here: http://www.biomedcentral.com/1471-2407/10/614/prepub

\section{doi:10.1186/1471-2407-10-614}

Cite this article as: Shahi et al:: Regulation of sonic hedgehog-GLI1 downstream target genes PTCH1, Cyclin D2, Plakoglobin, PAX6 and $N K X 2.2$ and their epigenetic status in medulloblastoma and astrocytoma. BMC Cancer 2010 10:614.

\section{Submit your next manuscript to BioMed Central and take full advantage of:}

- Convenient online submission

- Thorough peer review

- No space constraints or color figure charges

- Immediate publication on acceptance

- Inclusion in PubMed, CAS, Scopus and Google Scholar

- Research which is freely available for redistribution 